\title{
Assessing trust of suppliers' solutions offered in an electronic marketplace
}

\author{
by
}

Eduardo Moraes

A thesis submitted to the Faculty of Graduate Studies and Research in partial

fulfillment of the requirements for the degree of Master of Applied Science in

Technology Innovation Management

Department of Systems and Computer Engineering

Carleton University

Ottawa, Canada K1S 5B6

September 2010

C Copyright 2010 Eduardo Moraes 
Library and Archives

Canada

Published Heritage Branch

395 Wellington Street Ottawa ON K1A ON4 Canada
Bibliothèque et

Archives Canada

Direction du

Patrimoine de l'édition

395, rue Wellington

Ottawa ON K1A ON4

Canada
Your file Votre référence

ISBN: 978-0-494-71571-0

Our file Notre référence

ISBN: 978-0-494-71571-0
NOTICE:

The author has granted a nonexclusive license allowing Library and Archives Canada to reproduce, publish, archive, preserve, conserve, communicate to the public by telecommunication or on the Internet, loan, distribute and sell theses worldwide, for commercial or noncommercial purposes, in microform, paper, electronic and/or any other formats.

The author retains copyright ownership and moral rights in this thesis. Neither the thesis nor substantial extracts from it may be printed or otherwise reproduced without the author's permission.
AVIS:

L'auteur a accordé une licence non exclusive permettant à la Bibliothèque et Archives Canada de reproduire, publier, archiver, sauvegarder, conserver, transmettre au public par télécommunication ou par l'Internet, prêter, distribuer et vendre des thèses partout dans le monde, à des fins commerciales ou autres, sur support microforme, papier, électronique et/ou autres formats.

L'auteur conserve la propriété du droit d'auteur et des droits moraux qui protège cette thèse. Ni la thèse ni des extraits substantiels de celle-ci ne doivent être imprimés ou autrement reproduits sans son autorisation.
In compliance with the Canadian Privacy Act some supporting forms may have been removed from this thesis.

While these forms may be included in the document page count, their removal does not represent any loss of content from the thesis.
Conformément à la loi canadienne sur la protection de la vie privée, quelques formulaires secondaires ont été enlevés de cette thèse.

Bien que ces formulaires aient inclus dans la pagination, il n'y aura aucun contenu manquant. 


\begin{abstract}
Observations about 232 members of the Eclipse Marketplace and 16 suppliers' solutions are used to: (i) define a model to measure trust; (ii) implement an automated approach to calculate trust opinion values of suppliers' solutions offered in the marketplace; and (iii) produce insights on ways to increase belief and decrease customer's uncertainty about suppliers' solutions. Results suggest that trust values decrease customer uncertainty about a supplier's solution but do not increase customer belief in the solution.
\end{abstract}




\section{ACKNOWLEDGMENTS}

I would like to thank my supervisor, Prof. Tony Bailetti, for his incomparable patience and valuable support throughout the process of writing this thesis. For the priceless trust he held on me to complete this work, thank you.

To my wife Gislaine and my daughter Gabriela, that had understood without complain my absence during the hard work to complete my graduate program. 


\section{Table of Content}

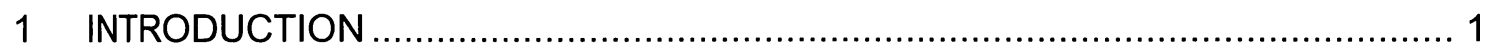

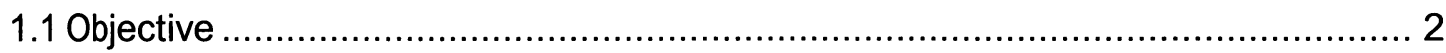

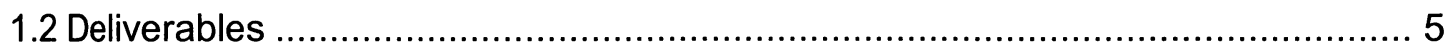

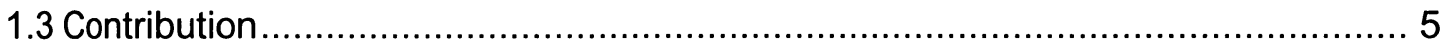

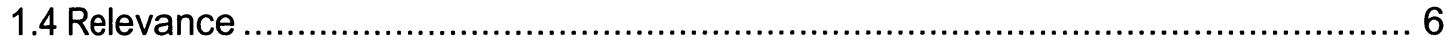

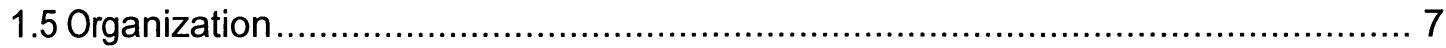

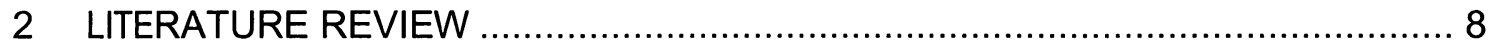

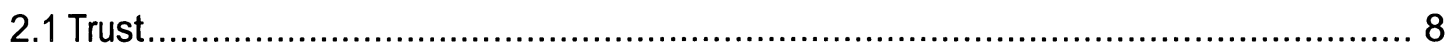

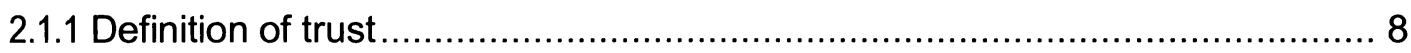

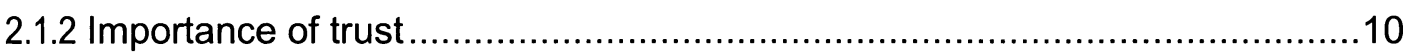

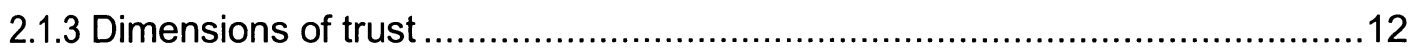

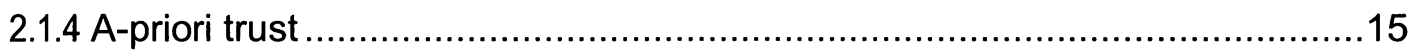

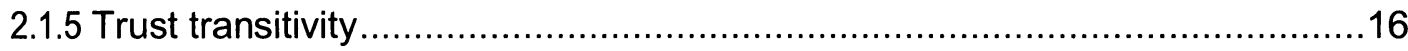

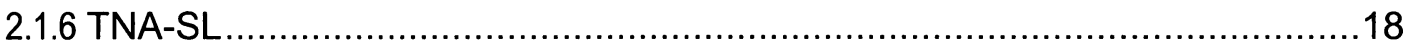

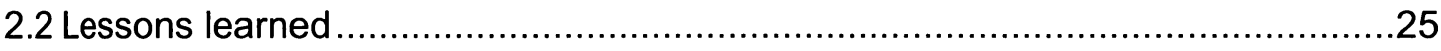

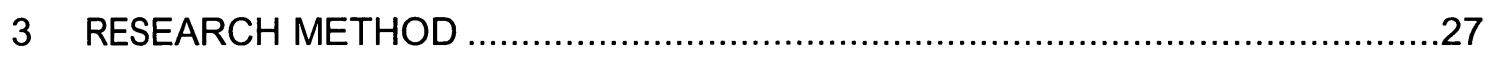

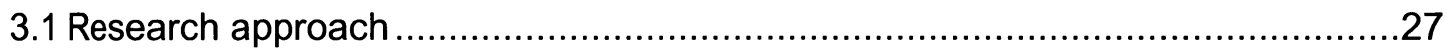

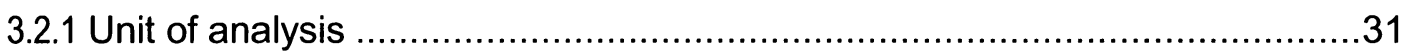

3.2.2 Source of data

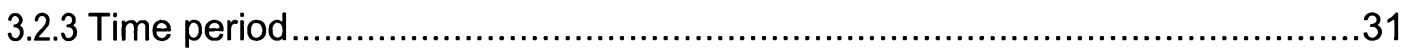

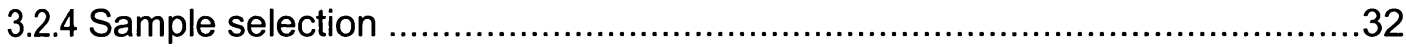

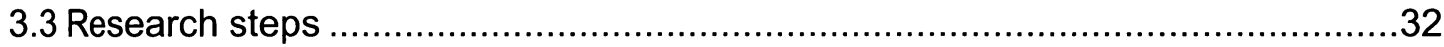

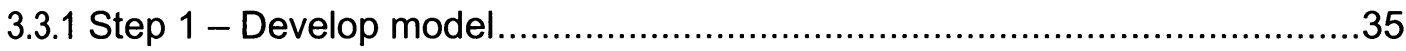

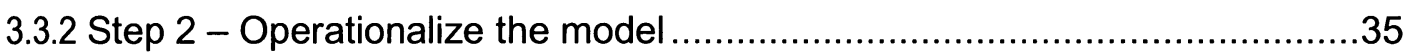

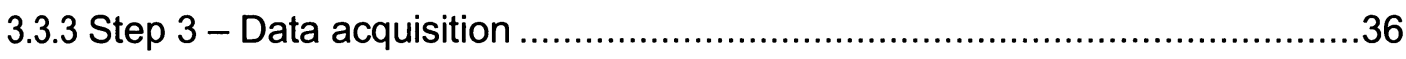

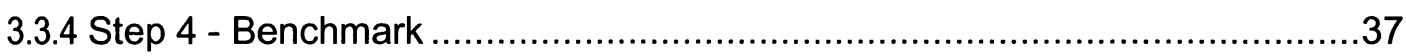

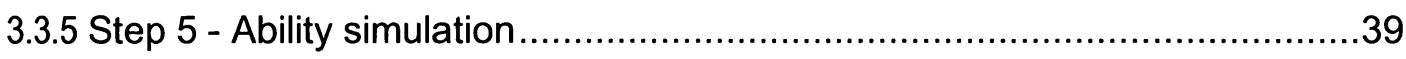

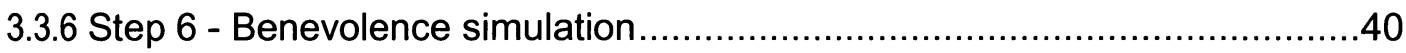

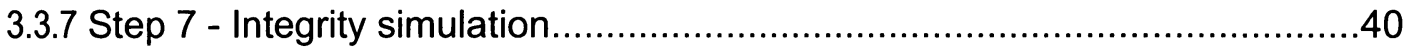

3.3.8 Step 8 - Combined simulation ................................................................ 41

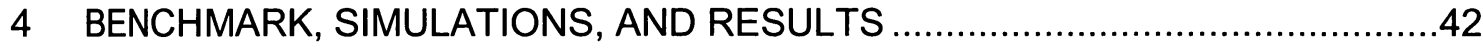

4.1 Step 1 - Develop model ............................................................................. 


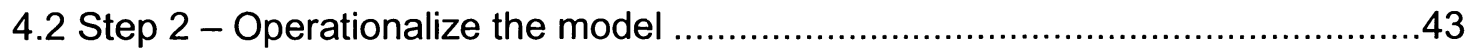

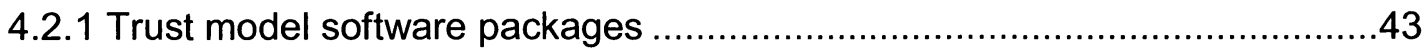

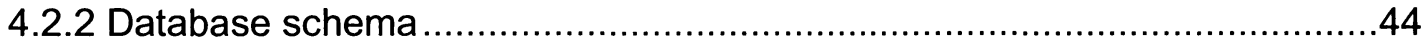

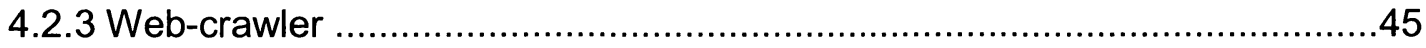

4.2.4 Trust network representation and computation of trust opinion values .........46

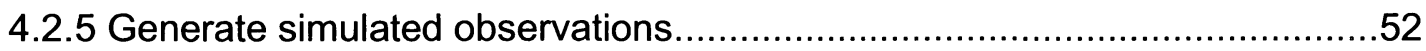

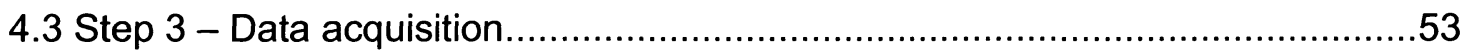

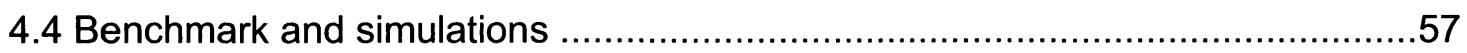

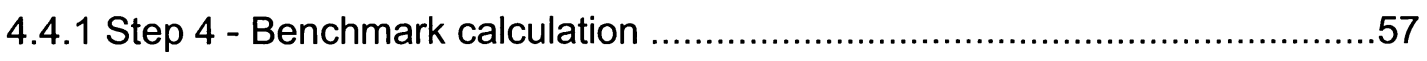

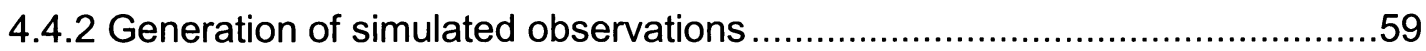

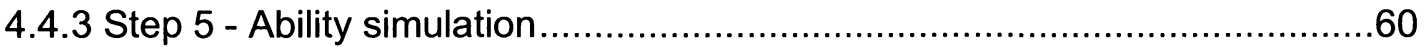

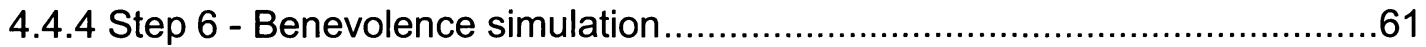

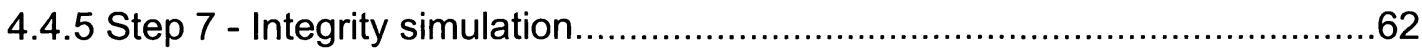

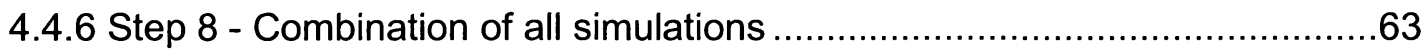

4.5 Step 9 - Comparing results of simulations and benchmark ............................64

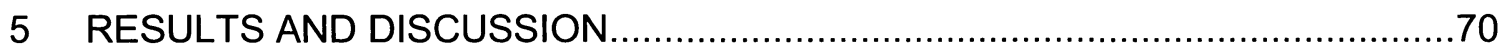

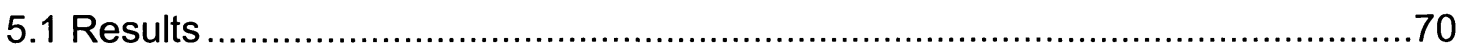

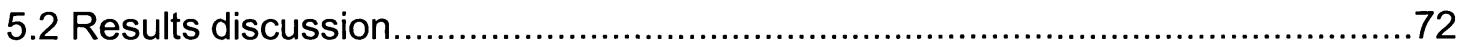

6 CONCLUSIONS, LIMITATIONS, AND FUTURE RESEARCH ........................

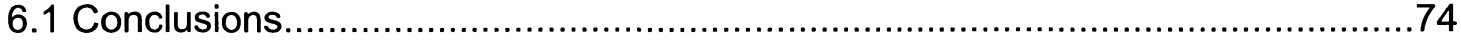

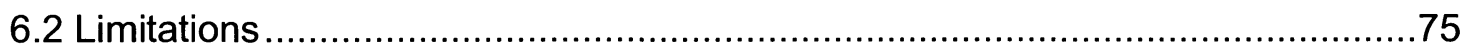

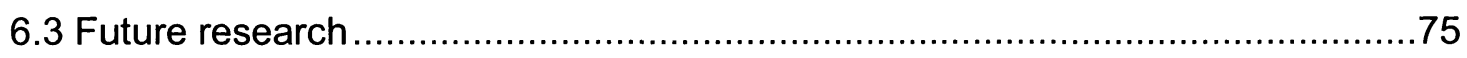

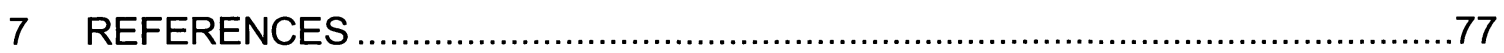




\section{List of Tables}

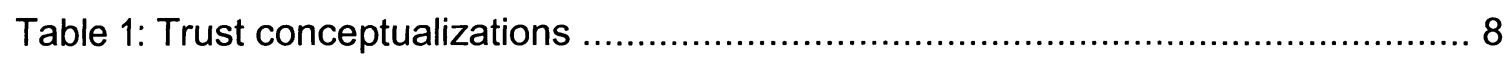

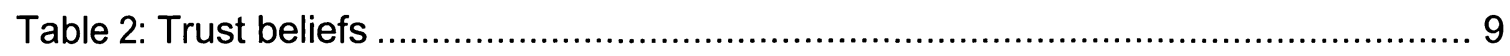

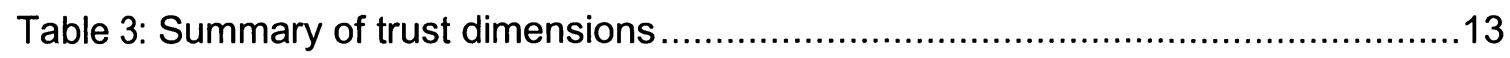

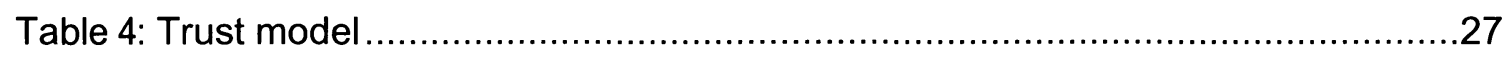

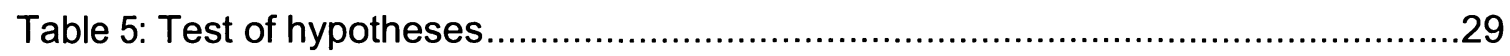

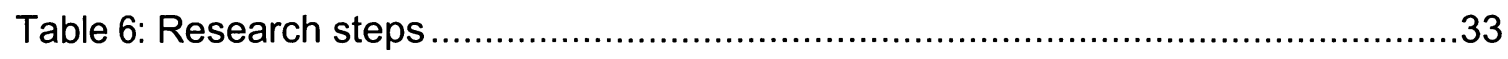

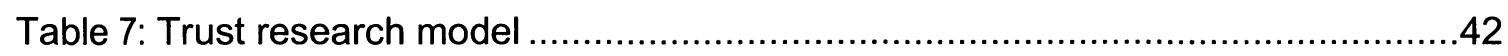

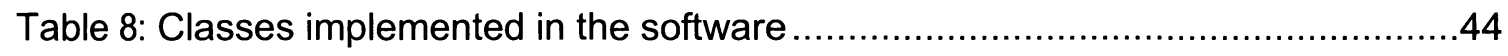

Table 9: Database tables used to collect and analyze data.....................................45

Table 10: Methods implemented in the class Web.java ........................................46

Table 11: Methods implemented in the class Arc.java ...........................................47

Table 12: Scope variants used to build the transitive trust network ............................49

Table 13: Parameters $r$ and $s$ used for trust opinion values calculation ......................50

Table 14: Methods implemented in the class Observation.java .................................53

Table 15: List of top 8 solutions with the most observations - scope S5 ......................54

Table 16: List of top 8 solutions with most observations - scope S15.........................55

Table 17: Benchmark results using only observation from the marketplace website ....59 
Table 18: Simulation results with simulated observations about the solution supplier's ability

Table 19: Simulation results with simulated observations about solution suppliers' benevolence

Table 20: Simulation results with simulated observations about solution suppliers' integrity

Table 21: Simulation results combining simulated observations on ability, benevolence, and integrity .63

Table 22: Belief values

Table 23: Relative impact on belief after simulation .65

Table 24: Uncertainty values .67

Table 25: Percentage change on uncertainty values after simulation .68 


\section{List of Figures}

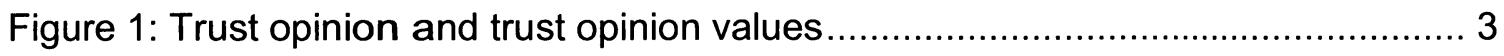

Figure 2: Klein's (2001) trust decision tree ................................................ 12

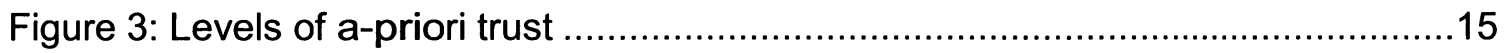

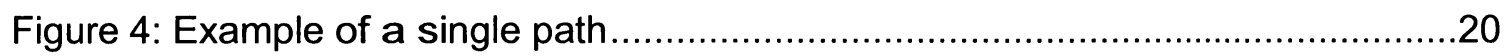

Figure 5: Example of two parallel trust paths .................................................20

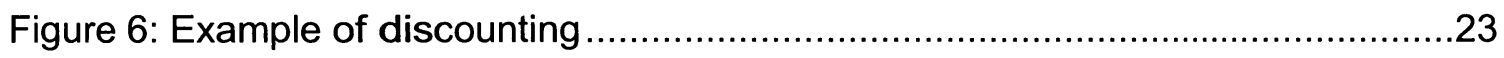

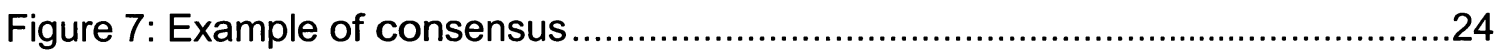

Figure 8: Relation between observations and trust opinion values $(\omega) \ldots \ldots \ldots \ldots \ldots \ldots . . . \ldots 30$

Figure 9: Customer's trust opinion values formula .........................................49

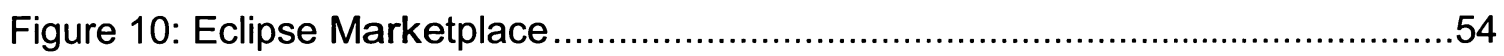

Figure 11: Example of reviews in Eclipse Marketplace ....................................56

Figure 12: Example of a list of members that have "favorited" a solution ..................56

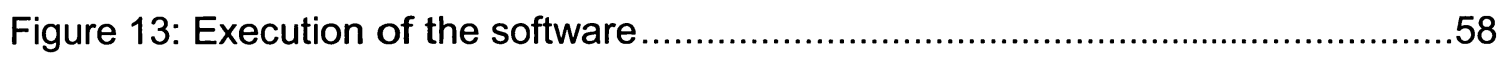

Figure 14: Relative impact of ability simulation on belief value .............................71

Figure 15: Trust path between customer and a solution in a marketplace .................99

Figure 16: Detailed trust model for a marketplace .....................................100 


\section{INTRODUCTION}

This research examines trust of suppliers' solutions published in a vendor neutral marketplace.

The problem being addressed is how to measure trust of solutions published in a marketplace operated by a keystone organization. A solution to this problem enables a keystone to increase trust of suppliers' solutions and reduce customers' uncertainty.

For the purpose of this research, a vendor neutral marketplace is a website operated by a keystone organization that is not dominated by a single supplier. The website allows its members to publish solutions and review solutions published by suppliers in the website.

A keystone is the organization that owns, operates, and evolves a platform (product, process, location, service or technology) and corresponding marketplace that deliver value to a community of members. The two main responsibilities of the keystone organization are to increase the: i) volume of transactions among members; and ii) efficiency of new product or service creation.

Marketplace members include suppliers, customers, investors, complementary service providers, and other organizations and individuals that benefit when suppliers sell to customers. A member is an individual or a company representative that has access to the marketplace. Members can publish their solutions in the marketplace and review other members' solutions. 
A solution is software created using the platform and distributed to customers using the marketplace.

A customer is a potential buyer of a solution that is visiting the marketplace.

Trust is essential to growing marketplaces. According to lansiti and Levien (2004):

"Trust is essential to good market operation because ultimately it decreases operating costs and risk exposure. A well-trusted marketplace will need to spend less in attracting customers and in managing their interactions, which means that it will be much easier to scale."

Traditionally, a supplier sells its solutions directly or through intermediaries. In a new approach a supplier can leverage the benefits of an established platform and a marketplace operated by a keystone.

\subsection{Objective}

The objective of this research is to examine: (i) how to measure trust of suppliers' solutions offered in a marketplace and (ii) which mechanisms increase customer belief and decrease customer uncertainty about solutions provided by suppliers.

Trust is measured using trust opinion values as defined in trust network analysis with subjective logic (Jøsang et al., 2006). 


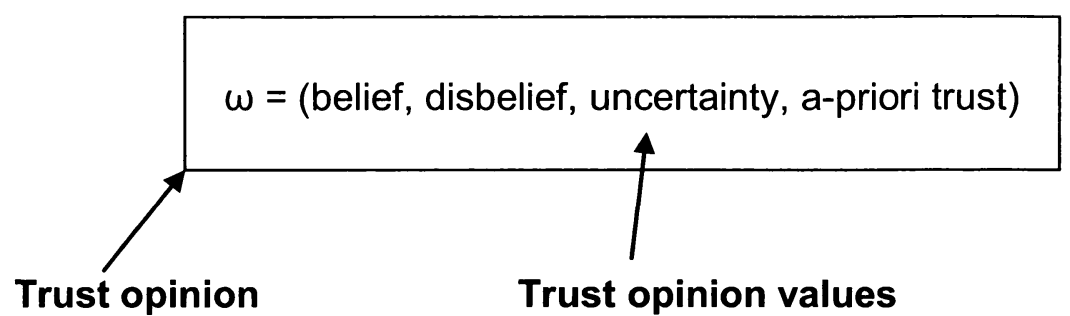

Trust opinion Trust opinion values

Figure 1: Trust opinion and trust opinion values

Figure 1 shows that a trust opinion $(\omega)$ is a vector of four values: belief, disbelief, uncertainty, and a-priori trust. Three of them (belief, disbelief, and uncertainty) are based on trust observations ${ }^{1}$. The fourth one (a-priori trust) is based on the truster's ${ }^{2}$ pre-disposition to trust.

Belief refers to the extent to which a truster believes that a trustee ${ }^{3}$ will deliver what was promised. Belief is calculated based on the number of positive and negative observations available on the trustee.

Disbelief refers to the extent of distrust from a truster to a trustee. Distrust defined as the incredulity that a trustee is able, reliable, and benevolent.

\footnotetext{
${ }^{1}$ Observations in trust network analysis with subjective logic are any positive or negative experiences of a truster about a trustee.

${ }^{2}$ Truster is the word used in the literature that refers to a person who establishes a trust relationship. Truster is the trust source also mentioned in the literature as "trustor" (Jøsang et al., 2006).

${ }^{3}$ Trustee is the word used in the literature that refers to a person who receives trust from a truster. Trustee is the trust target (Jøsang et al., 2006).
} 
Uncertainty is the lack of observations about a solution supplier. The higher the customer uncertainty about a solution supplier, the lower the customer's willingness to close a deal ${ }^{4}$.

A-priori trust determines the initial trust placed on a member of the community in the absence of any positive or negative observations.

Two hypotheses are advanced to examine whether or not providing additional observations on a solution supplier's ability, integrity, and benevolence help decrease customer's uncertainty and increase customer's belief about the supplier's solution.

Hypothesis 1. Additional observations on a solution supplier's ability, integrity, and benevolence decrease customer's uncertainty about the supplier's solution.

Hypothesis 2. Additional observations on a solution supplier's ability, integrity, and benevolence increase customer's belief about the supplier's solution.

To test the two hypotheses and answer the research question, we use trust network analysis with subjective logic (TNA-SL). TNA-SL enables the operationalization of a model to measure and analyze trust opinion values about information on solutions published in a marketplace.

The Eclipse Marketplace website (http://marketplace.eclipse.org) is the source of the data used in this research.

\footnotetext{
${ }^{4} \mathrm{~A}$ deal is a successful business transaction between a customer and a solution supplier.
} 
This research uses 621 observations on members and suppliers' solutions inferred from information collected from the Eclipse Marketplace website. Observations are about 232 members, and 16 solutions drawn from 2 solution categories in the Eclipse Marketplace named: documentation and team development.

\subsection{Deliverables}

This research delivers:

1. A model to measure trust in suppliers' solutions offered in a marketplace.

2. An approach to automatically calculate trust values of solutions offered in a marketplace.

3. Insights on ways to increase belief and decrease a customer's uncertainty about a solution offered in a marketplace.

\subsection{Contribution}

The results of this research are expected to provide the following benefits:

1. Benefits of results of thesis

a) Expand Jøsang's (2006) trust network analysis model by incorporating research carried out by Mayer et al. (1995).

2. Future potential benefits

a) Reduce costs of transactions among members who access a marketplace

b) Increase the number of deals closed by marketplace customers 
Transaction costs can be reduced by providing trust opinion values. The trust opinion values add information that potential customers can use to close deals in a marketplace.

Increased trust values reduce uncertainty for customers about suppliers' solutions and foster the number of deals being closed in the marketplace.

Jøsang's trust network analysis model is expanded by deriving trust opinions based on observations on suppliers' ability, integrity, and benevolence. These are the three trust dimensions proposed by Mayer et al. (1995).

\subsection{Relevance}

This research is relevant to marketplace members because it provides an approach to calculate trust opinion values of the solutions offered in the marketplace operated by the keystone. These trust opinion values are visible and may be able to reduce members' search and information costs.

This research is relevant to operators of keystones for two reasons. First, the research can guide a keystone to help its members increase trust in their solutions. Second, the research shows how the keystone can increase the trust that organizations place on the solutions offered in its marketplace.

This research is also relevant to academics for two reasons. First, the research provides concrete examples of how to calculate trust opinion values in a real marketplace. Second, this research brings together two separate literature streams: 
trust network analysis with subjective logic model proposed by Jøsang et al. (2006) and the trust dimensions analysis by Mayer et al. (1995).

\subsection{Organization}

This thesis is organized into six chapters. The first chapter is the introduction. The second chapter reviews the literature on trust. The third chapter describes the method and simulation model used in this research. The fourth chapter presents the results of the simulation. The fifth chapter discusses the research findings. Finally, chapter six provides the conclusions, research limitations and suggestions for future research. 


\section{LITERATURE REVIEW}

\subsection{Trust}

Chapter 2 is organized into two sections. Section 2.1 presents a literature review on the definition, importance, dimension, and transitivity of trust. Section 2.2 presents the lessons learned from the literature review.

\subsubsection{Definition of trust}

Trust has been conceptualized in at least five ways. Table 1 identifies the five conceptualizations found in the literature.

\section{Table 1: Trust conceptualizations}

\begin{tabular}{|c|c|}
\hline Conceptualization of trust as: & Researchers \\
\hline Willingness to take risk & $\begin{array}{l}\text { Pardue et al., 2008; Svensson \& Wood, 2004; } \\
\text { Levin et al., 2006; Mcknight et al., 1998; } \\
\text { Shoorman et al., 2007; Das \& Bing-Sheng } \\
\text { Teng, 1998; Jøsang et al., 2006; Mayer et al., } \\
1995\end{array}$ \\
\hline Confidence & $\begin{array}{l}\text { Klein, 2001; Ring \& Van de Ven, 1992; Ring \& } \\
\text { Van de Ven, } 1994\end{array}$ \\
\hline Belief & $\begin{array}{l}\text { Dirks \& Ferrin, 2001; Shi et al., 2004; Mouzas } \\
\text { et al., 2007; Pavlou \& Dimoka, 2006; Huang \& } \\
\text { Nicol, 2009 }\end{array}$ \\
\hline Psychological state & $\begin{array}{l}\text { Huang \& Nicol, 2009; Huang \& Fox, 2006; } \\
\text { Dirks \& Ferrin, } 2001\end{array}$ \\
\hline Multi-faceted concept & $\begin{array}{l}\text { Ratnasingam, 2005; Nooteboom, 2004; } \\
\text { Olekalns \& Smith, } 2007\end{array}$ \\
\hline
\end{tabular}


Mayer et al. (1995) describe trust as "the willingness of a party to be vulnerable to the actions of another party based on the expectation that the other will perform a particular action important to the truster, irrespective of the ability to monitor or control that other party". The definition of trust proposed by Mayer et al. (1995) is accepted by many authors (Pardue et al., 2008; Svensson \& Wood, 2004; Levin et al., 2006; Mcknight et al., 1998; Shoorman et al., 2007; Das \& Bing-Sheng Teng, 1998; Jøsang et al., 2006).

A second group of researchers conceptualize trust as the level of confidence on another's goodwill (Klein, 2001; Ring \& Van de Ven, 1992; Ring \& Van de Ven, 1994).

A third group of researchers conceptualize trust as a belief (Dirks \& Ferrin, 2001; Shi et al., 2004; Mouzas et al., 2007; Pavlou \& Dimoka, 2006; Huang \& Nicol, 2009). Table 2 provides a list of trust beliefs found in the literature.

\section{Table 2: Trust beliefs}

"Belief that one can rely upon another person's actions and words and/or that the person has good intentions toward oneself"

"Belief that the actions of another may be relied upon, without explicit guarantee, to achieve a goal in a risky situation"

Shi, J., \& Bochmann, G. v., \& Adams, C. (2004)

"Belief or sentiment that the other party will act benevolently" Mouzas, S., \& Henneberg, S., \& Naudé, P. (2007)

"Belief that a transaction with a seller will occur in a manner consistent with her confident expectations"

Pavlou, P. A., \& Dimoka, A. (2006)

"[Belief] that the expected behavior occurs, based on the evidence of the trustee's competence and goodwill"

Huang, J., \& Nicol, D. (2009) 
Huang and Nicol (2009), Huang and Fox (2006), and Dirks and Ferrin (2001) define trust as a psychological state comprising three elements: expectancy, belief, and willingness to be vulnerable. Such definition is aligned with the definition of trust advanced by Mayer et al. (1995).

A last group of researchers defines trust as a multi-faceted configuration. Ratnasingam (2005) conceptualizes trust as comprised of technological, economic, behavioural, and organizational perspectives. Nooteboom (2004) and Olekalns and Smith (2007) consider the behavioural facet of trust and divide it in two main aspects: competence trust and good-will or intentional trust. Competence trust is derived from a trustee's ability or competence. Good-will or intentional trust is derived from a trustee's intention, benevolence and integrity.

\subsubsection{Importance of trust}

Trust is considered to be the most important phenomenon that contributes to the strength and maintenance of fruitful personal and business relationships (Svensson \& Wood, 2004). It facilitates conclusion of transactions by diminishing the necessity of undesired mechanisms of control. It can be a "low-cost substitutes for police, regulators, and court actions" (Yandle, 2010).

As trust is built and maintained there is no need for constant on-going verification of another party's trustworthiness. Trust is fundamental to the development and sustainability of a market (lansiti \& Levien, 2004). When significant demands for trust verification are in place, "the transaction costs are increased to a level that makes much cooperation less rewarding, and some is inhibited" (Tullberg, 2008). 
Trust can help reduce transaction costs of an exchange (Poel, 2005; Ratnasingam, 2005). Poel (2005) argues:

"Trust can reduce transaction costs (Chiles \& McMackin, 1996 in Poel, 2005). When there is a high level of trust between two parties, contract costs are lower because it is not necessary to include all kinds of costly safeguards. Moreover, negotiation costs are lower because when people trust each other they are more willing to cooperate with each other and they do not have to find out whether the other is a trustworthy person. Furthermore, the monitoring costs are reduced, because it is no longer necessary to check every time whether the other is really doing what he promised to do."

Lack of trust results in a pay-off of zero for all players and prevents society from achieving outcomes (Klein, 2001). Figure 2 represents the trust decision tree as proposed by Klein (2001). If a truster makes a decision not to trust a promise the result is 0 for both truster and promiser. If the truster decides to trust and the promiser keeps its promise both players win. 


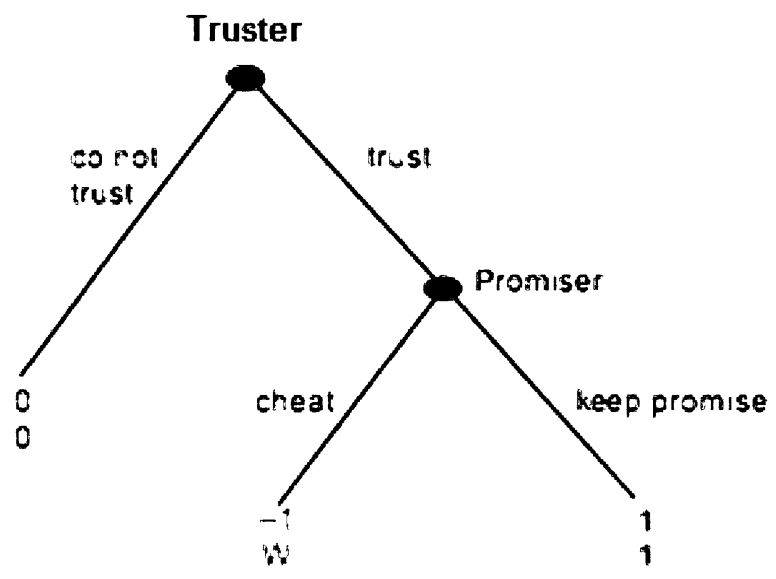

Figure 2: Klein's (2001) trust decision tree

\subsubsection{Dimensions of trust}

Trust dimensions include the perception of someone's ability, integrity, and benevolence (Mayer et al., 1995; Levin et al., 2006; Shoorman et al., 2007; Olekalns \& Smith, 2007; Pardue et al.,2008). These factors are also defined as good-will and reliability (Das \& Teng, 1998); good-will and compentece (Huang \& Nicol, 2009); and as integrity or good-will (Ring \& Van de Ven, 1994).

Mcknight et al. (1998) distinguish between trusting intention and trusting beliefs and identify three trusting beliefs: benevolence, competence, and honesty or predictability. Olekalns and Smith (2007) also list reliability, predictability, benevolence and integrity as relational risks drawn from theories of interpersonal perception, social exchange and trust. Pavlou and Dimoka (2006) list benevolence and credibility. 
Nooteboom 's multi-faceted concept of trust has ability as a dimension of competence trust and dedication plus benevolence as dimensions of intentional trust (Nooteboom, 2004).

Shoorman et al. (2007) noted that "just as perceptions about an individual's ability, benevolence, and integrity will have an impact on how much trust the individual can garner, these perceptions also affect the extent to which an organization will be trusted."

Table 3 provides the dimensions of trust identified in the literature and their associated concepts.

\section{Table 3: Summary of trust dimensions}

\begin{tabular}{|l|l|}
\hline $\begin{array}{l}\text { Mayer et al. (1995) } \\
\text { trust dimensions }\end{array}$ & Associated concepts \\
\hline Ability & Competence (Huang \& Nicol, 2009; Ratnasingam, 2005) \\
\hline Integrity & $\begin{array}{l}\text { Reliability (Das \& Teng, 1998) } \\
\text { Honesty (Mcknight et al., 1998) } \\
\text { Predictability (Mcknight et al., 1998; Olekalns \& Smith, 2007; } \\
\text { Ratnasingam, 2005) } \\
\text { Credibility (Pavlou \& Dimoka, 2006) }\end{array}$ \\
\hline Benevolence & $\begin{array}{l}\text { Goodwill (Das \& Teng, 1998; Ring \& Van de Ven, 1994; Pavlou } \\
\text { \& Dimoka, 2006; Ratnasingam, 2005) } \\
\text { Willingness (Mouzas et al., 2007) } \\
\text { Confidence (Das \& Teng, 1998) } \\
\text { Intentionality (Ratnasingam, 2005) }\end{array}$ \\
\hline
\end{tabular}




\subsubsection{Ability}

Ability can be defined as the truster's belief that a trustee is able to deliver a given product or service in a given manner. The trustee has competence to deliver what is in the scope of the transaction.

\subsubsection{Integrity}

Integrity is the truster's belief that the trustee adheres to a set of common accepted principles (Pardue et al., 2008).

While ability "only assures that the supplier could perform. This does not mean that it will perform, and, therefore, the supplier will not necessarily be trusted. The perception that the supplier has integrity suggests that it will fulfill agreements as promised." (Shoorman et al, 2007)

\subsubsection{Benevolence}

Benevolence is "the extent to which a party is believed to want to do good for the trusting party, aside from an egocentric profit motive" (Shoorman et al., 2007).

When applying it to online marketplaces, benevolence can be defined as "the buyer's belief that a seller has beneficial motives, is genuinely concerned about the buyers' interests, and will act in a goodwill manner beyond short-term profit expectations" (Pavlou \& Dimoka, 2006). 
Benevolence is the truster's belief that the trustee wants to do what is good to the truster beyond egocentric profit motives (Pardue et al., 2008).

\subsubsection{A-priori trust}

Initial trust depends on the truster predisposition to trust (basic or a-priori trust) and in the evidence he or she has to trust the other party (direct and indirect trust).

Basic trust is comprised of all past experiences of the truster (Marsh, 1994; Shi et al., 2004). Jøsang et al. (2006) call it a-priori trust. Figure 3 illustrates. Value of a-priori trust ranges between 0 and 1 , where 0 means that the truster $A$ has no pre-disposition at all to trust party B, and 1 means that, even in the lack of any evidence, truster totally trusts party B.

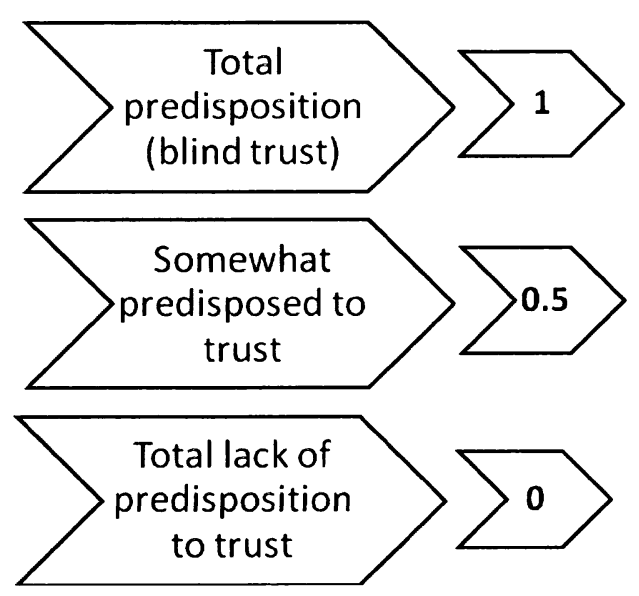

Figure 3: Levels of a-priori trust 


\subsubsection{Trust transitivity}

Trust can be direct or indirect (Jøsang et al., 2006; Shi et al., 2004; Pardue et al., 2008).

Direct trust is established from the truster direct experiences with another party, while indirect trust is derived from recommendations made by others (Jøsang et al., 2006; Shi et al., 2004; Pardue et al., 2008).

Indirect trust is established by deriving trust from someone else's trust. "Derive trust" refers to a truster formulating a trust opinion based on other's trust opinions.

Trust transitivity is the use of indirect trust in trust networks (Lifen, 2008; Jøsang et al., 2006).

There are situations where one can't rely solely in past experience and direct observations to make a trust decision. For example, when someone has no expertise on a specific domain, then relying on opinions of experts and on the reputation of the trust object is a totally acceptable way of compiling information that would help the process of decision-making. The weight applied to such opinions will depend in how much the truster also trusts the source of those opinions. Consequently, even though he or she won't take the provided trust opinion as a final value for his or her decision, that opinion will collaborate with a certain degree of influence in his final decision.

Ring and Van de Ven (1992) recognize that reputation is necessary for trust. Trust is more likely to be extended to an organization when that organization earns a reputation 
for following norms of equity. However, reputation is not the only factor that affects trust (Ring and Van de Ven, 1992).

Yandle (2010) examined the trust lost due to the financial collapse of 2007-2009. Yandle argues that mechanisms that ensure trust include "the reputational capital of the service firm or owner, and recommendations from other customers of repair services that can be assessed directly only through experience".

Pardue et al. (2008) state that "trusters communicate their perceptions of the trustworthiness of a trustee to other trusters in online reputation systems". However, interestingly they also noted that most of these communications tend to make reference to the truster's perception of the trustee's ability and integrity. The benevolence dimension had only a small number of references.

Jøsang et al. (2006) propose that trust transitivity can be measured using trust network analysis with subjective logic. In a trust network, trust opinions expressing someone's belief, disbelief and uncertainty about a trustee in a given situation can be derived from a combination of other parties' trust opinions when they are in the same trust path.

A trust path is a sequence of trusters and trustees on a given trust scope. For example, A trusts $B$ that trusts $C$ is a trust path between $A$ and $C$.

Chandrasekharan and Esfandiari (2000) affirm that "formally, the trust relation is not transitive". But they recognize the potential transitivity of trust when they propose that "however, trust is considered weakly transitive, in the following sense: there is a probability that $A$ might trust $C$, if $B$ recommends $C$ to $A$ for action $X "$. That is in the 
sense that A will use B's observations as part of the parameters to formulate its own trust level about C, which is compatible with Jøsang et al. (2006).

\title{
2.1.6 TNA-SL
}

Trust opinion values can be calculated using trust network analysis with subjective logic (TNA-SL). In a trust network, people, organizations and software agents can derive indirect trust in other parties from the members of the trust network. Jøsang et al. (2006) describe an approach to measure derived indirect trust opinion values. TNA-SL consists of the following elements:

1. A concise notation to represent trust transitivity in a trust network

2. A method for simplifying complex trust networks so that they can be expressed in a concise form

3. Trust measures expressed as opinions, so that derived indirect trust can be automatically and securely computed using subjective logic

\begin{abstract}
A trust network is comprised of participants that can derive trust from other participants in the same trust path. A trust path is a set of trust arcs between two parts.
\end{abstract}

A trust arc establishes the relationship between two parties: the truster and the trustee. The truster is a person or a group that makes a trust decision. The trustee can be a person, group, company, product or service. 
A trust path can be direct or indirect. A direct trust path means that the truster trusts the trustee directly from experience with him. Direct trust paths have a single trust arc. An indirect trust path means that the truster is using one or more parties as referral to the trustee. Indirect trust paths have multiple trust arcs.

Derived trust measures are obtained using other parties' trust opinions in an indirect trust path.

Figure 4 illustrates that Alice has derived indirect functional trust (if-trust) in Charlie. Alice trusts Bob as someone that can refer her to a good mechanic who can repair her car. Bob trusts Charlie as a good mechanic. Figure 4 shows that Alice has direct trust in Bob, who has direct trust in Charlie. Consequently, Alice can derive from Bob indirect trust in Charlie. That is possible because the trust that Alice has in Bob is specific to the scope of being a referral for a good mechanic.

Scope is defined as "the specific type(s) of trust assumed in a given trust relationship" (Jøsang et al., 2006). The direct trust that Alice has in Bob is an example of direct referral trust. The direct trust Bob has in Charlie is an example of direct functional trust.

The scope of a trust arc defines what the truster trusts the trustee. One may trust another party as a really good professor, but may not trust that same party for piloting an airplane or executing a cyrurgic intervention. It is based on what exactly the trustee is promising to deliver. 
Scope: "a good mechanic"

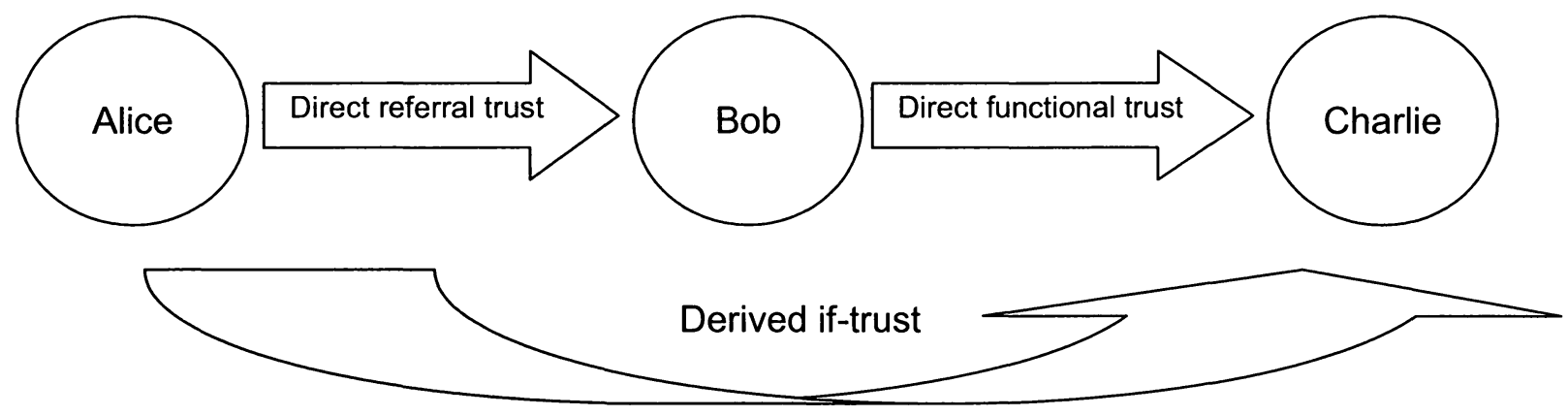

Figure 4: Example of a single path

It is also possible to combine multiple referrals in a parallel trust combination. Let's say Alice knows both Bob and David. Both of them had recommended Charlie as a good mechanic. Therefore, now there is a combination of two possible trust paths from Alice to Charlie, one being derived from Bob and another one being derived from David. Assuming Alice trusts both, this additional trust path would help increase her indirect trust in Charlie.

Figure 5 represents the two parallel trust paths.

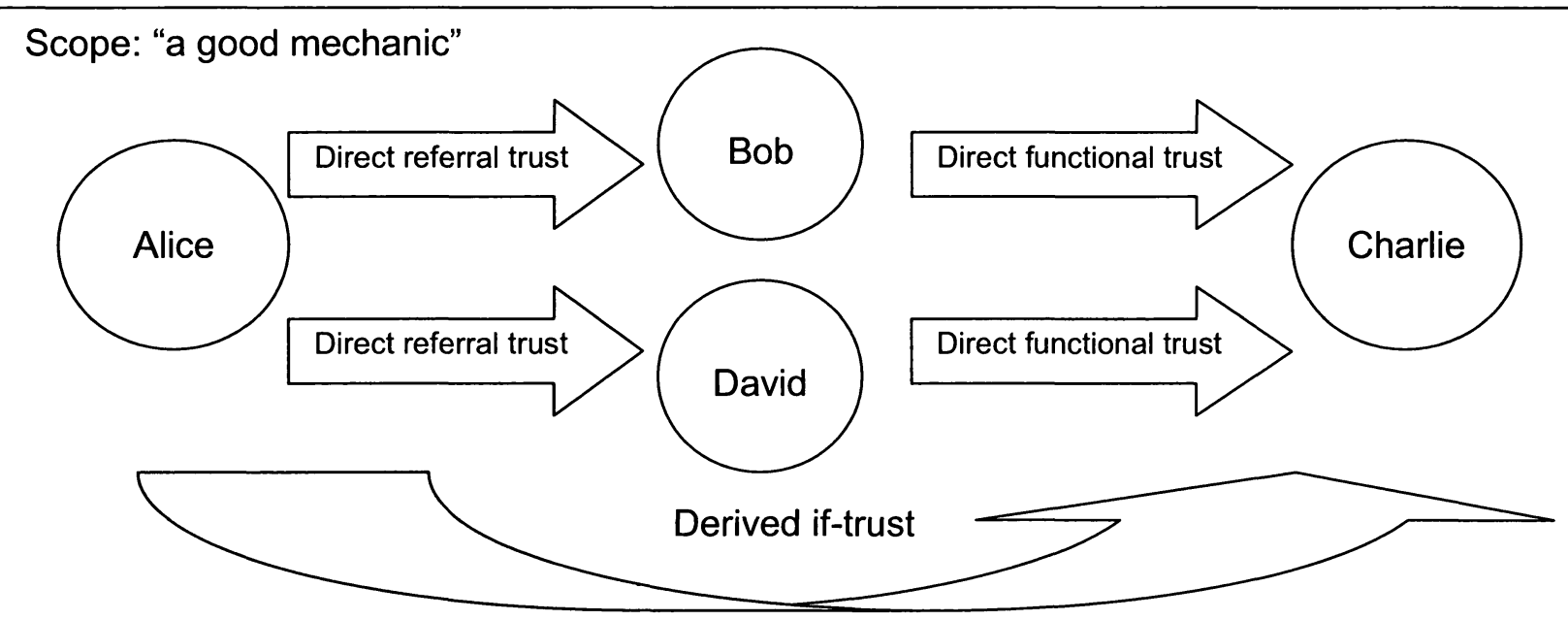

Figure 5: Example of two parallel trust paths 
In TNA-SL, canonical expressions are used to define trust paths. Canonical expressions are representations "of a trust graph in structured notation where every arc only appears once" (Jøsang et al., 2006).

\subsubsection{Belief, Disbelief, and Uncertainty}

Huang and Nicol (2009) had established a relationship between the dichotomy beliefdisbelief with trust-distrust. An additional element to such relationship is the uncertainty attribute (Jøsang et al., 2006).

\section{Belief}

Belief in subjective logic refers to the amount of belief in support of the affirmation "A trusts B about S" as being true (Jøsang, 2009). Using the example illustrated in Figure 6 , it would be Alice's belief that Charlie is a good mechanic.

\section{Disbelief}

Disbelief in subjective logic refers to the amount of belief in support of the affirmation "A trusts B about S" as being false (Jøsang, 2009). Using the example from Figure 5, disbelief refers to Alice's belief on Charlie as a not good mechanic.

\section{Uncertainty}

Uncertainty refers to a situation where there is no evidence to support of the affirmation "A trusts B about S" as being true or false. In Figure 5, uncertainty refers to Alice's uncertainty that Charlie is a good mechanic. 
According to Das and Teng (1996) "trust is instrumental in reducing uncertainty".

\subsubsection{Trust Opinions}

In TNA-SL, a trust opinion expresses the belief that the truster has about a given scope based on the evidence that he or she has available. A trust opinion is a vector of values ranging from 0 to 1 representing belief, disbelief, uncertainty, and the a-priori trust value.

A trust opinion is based on evidence that the truster has and that leads the truster to believe that the trustee will deliver what is being promised. It is only when one party has evidence to trust another party that the trust relation is established. The evidence can be based on observations from the direct experience between the parties (direct trust), or on observations of other parties about the trustee (indirect trust). Even when there is no apparent reason or evidence for trusting another party in an initial relationship, it is actually the truster's past experience and disposition to trust (a-priori trust) that will guide a final decision on whether or not to trust (McKnight et al., 1998; Marsh, 1994).

\subsubsection{Computing Transitivity}

Trust opinion values on direct trust relationships are computed based on the number of positive observations from one party to another (represented by the letter $r$ ), and the number of negative observations from one party to another (represented by the letter s).

A trust opinion for an indirect derived trust is computed in TNA-SL using two methods: discounting and consensus. 


\section{Discounting}

Discounting refers to the method to calculate a trust opinion that results from a transitive indirect trust path. Figure 6 illustrates discounting. The symbol $\otimes$ is used to represent discounting.

Scope: "a good mechanic"

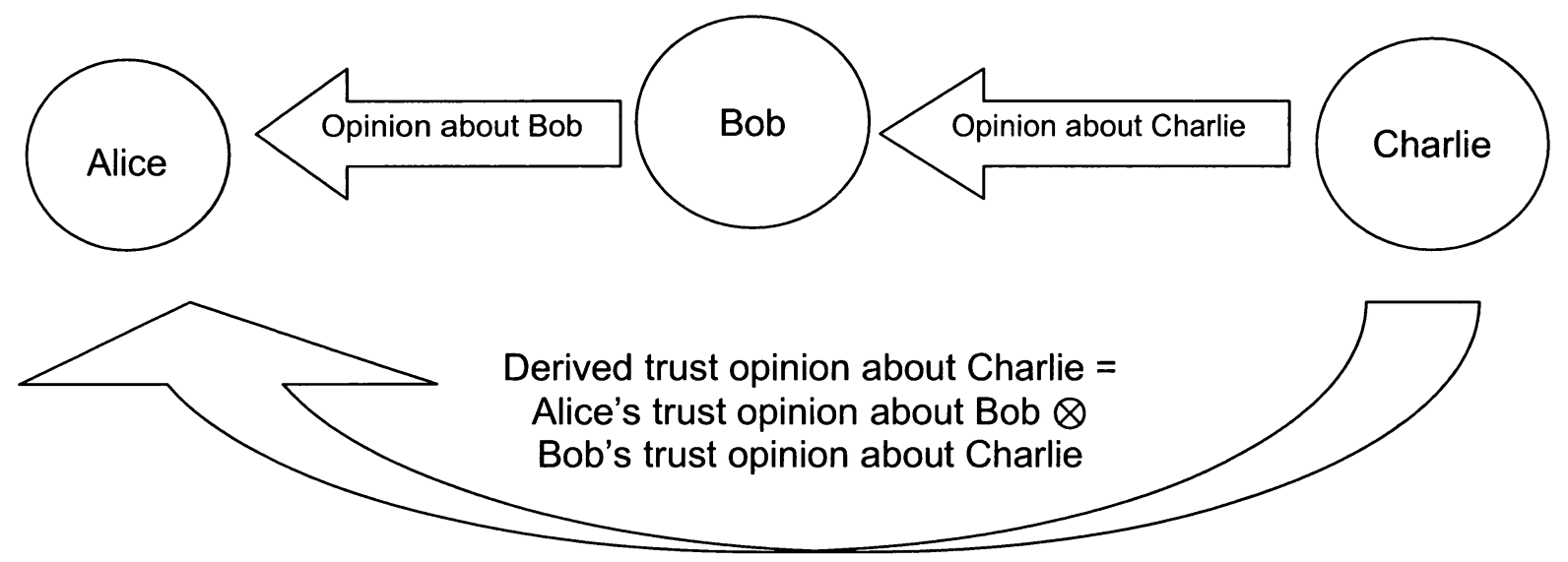

Figure 6: Example of discounting

Alice derives her trust opinion about Charlie through Bob. Alice's trust opinion about Bob is used to discount Bob's trust opinion about Charlie. 


\section{Consensus}

Consensus is a combination of different trust opinions about the same trustee and in the same scope. Consensus represents a consensual derived trust opinion. As a result, the consensus operator amplifies belief and/or disbelief and reduces uncertainty. Figure

7 illustrates how consensus is obtained. The symbol $\oplus$ is used to represent consensus.

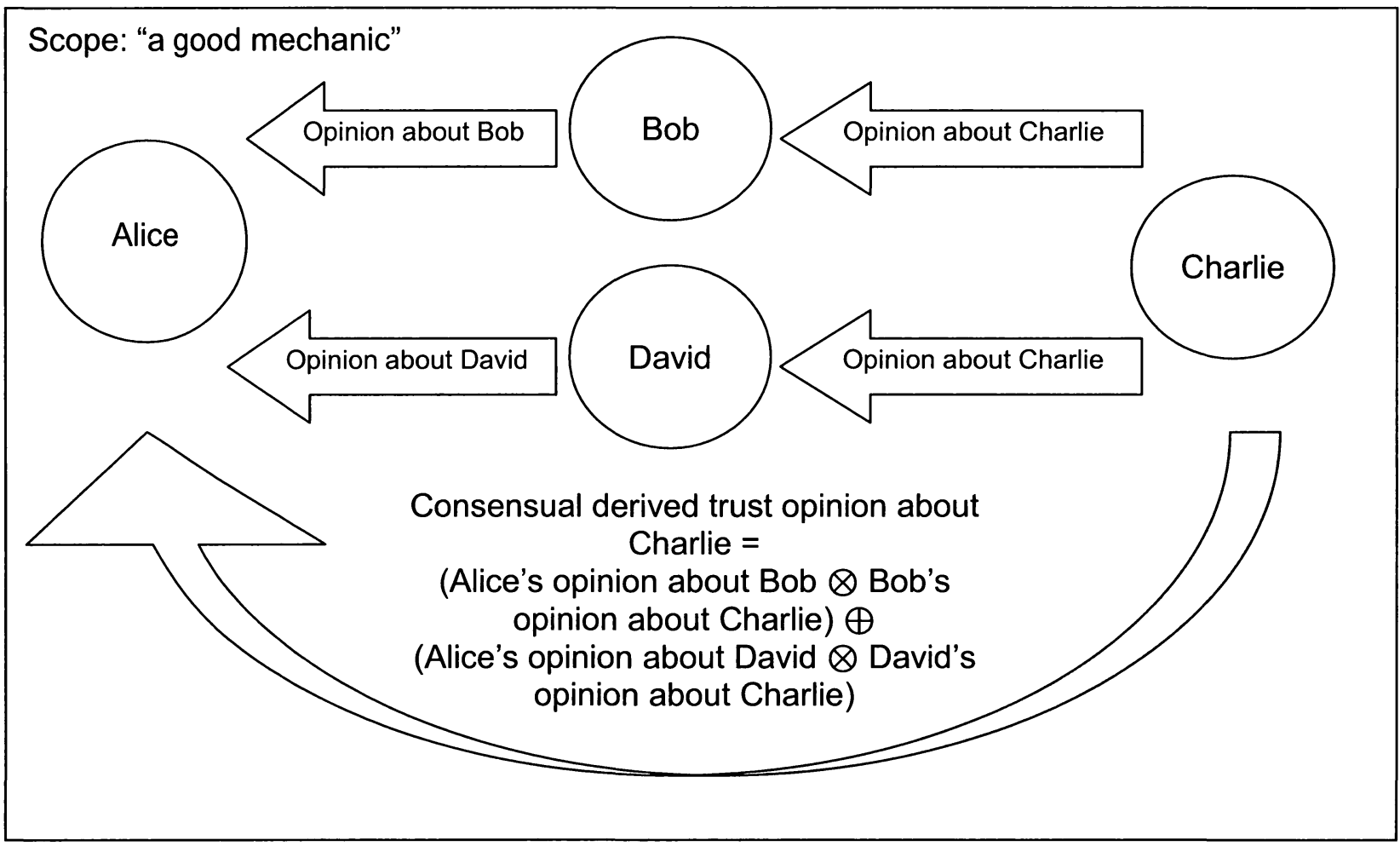

\section{Figure 7: Example of consensus}

Alice derives her trust opinion about Charlie through Bob and David. Alice's trust opinion about Bob is used to discount Bob's trust opinion about Charlie. Alice's trust opinion about David is used to discount David's trust opinion about Charlie. The two discounted trust opinions are brought together by the consensus operator. 


\subsubsection{Risk}

Risk is the variable used by the truster to take the final decision to trust or not trust the trustee. The truster first will take in consideration the reasons he or she has to trust the trustee and then decides whether or not to involve the trustee regarding the particular scope.

\subsection{Lessons learned}

The lessons learned from the literature review are:

- Trust is an important element in relationships. Lack of trust results in a pay-off of zero for customers and suppliers. Lack of trust prevents society from achieving outcomes.

- Trust has three main trust dimensions: ability, integrity and benevolence

- Transitive trust values can be measured using trust network analysis with subjective logic (TNA-SL). Subjective Logic offers a way to easily represent transitivity in trust networks and calculate trust opinion values that will represent a degree of belief, disbelief, and uncertainty in a transaction.

- Transitivity is an important concept to understand reputation systems and to measure trust opinion values in a marketplace.

- Negative and positive observations about trustees can be used to calculate trust opinion values.

- Multiple trust opinions in a same trust path can be combined using the consensus and discounting operators provided by TNA-SL. 
- Literature doesn't provide the connection between trust dimensions and trust transitivity. Jøsang's trust network analysis model can be used to calculate trust opinions based on observations on the three trust dimensions proposed by Mayer et al. (1995): ability, integrity, and benevolence.

- Without trust transaction costs increase (Tullberg, 2008).

- Trust is a low-cost substitute for police, regulators, and court actions, and can reduce transaction cost (Yandle, 2010). Negotiation costs are lower when people trust each other. Monitoring costs are reduced, because constant check on other party trustworthiness is no longer necessary (Poel, 2005).

- Trust is essential to good market operation. A well-trusted marketplace spends less in attracting customers and in managing their interactions (lansiti \& Levien, 2004).

- The number of deals can be increased as increased trust reduces uncertainty for customers about suppliers' solutions. Trust is instrumental in reducing uncertainty (Das \& Teng, 1996). 


\section{RESEARCH METHOD}

Chapter 3 describes the method used to carry out this research. It is organized into three sections. Section 3.1 describes the research approach. Section 3.2 provides the research design. Section 3.3 describes the steps undertaken to carry out the research.

\subsection{Research approach}

Information is collected from the Eclipse Marketplace and used to infer observations about members and solutions.

Observations are used to calculate trust opinion values (belief, disbelief, and uncertainty) in direct trust arcs in a trust network.

Table 4 presents the trust model that anchors the hypotheses to be advanced.

\section{Table 4: Trust model}

\begin{tabular}{|l|l|c|c|}
\hline Independent variables & \multicolumn{3}{|c|}{ Dependent Variables } \\
\hline $\begin{array}{l}\text { Positive and negative } \\
\text { observations on solution } \\
\text { supplier's trust dimensions } \\
\text { (Mayer et al.,1995): }\end{array}$ & \multicolumn{3}{|c|}{$\begin{array}{c}\omega \text { (trust opinion values) } \\
\text { (Jøsang et al., 2006) }\end{array}$} \\
\hline Ability + Integrity + Benevolence & $\begin{array}{c}\text { Uncertainty } \\
\text { value }\end{array}$ & $\begin{array}{l}\text { Belief } \\
\text { value }\end{array}$ & $\begin{array}{c}\text { Disbelief } \\
\text { value }\end{array}$ \\
\hline
\end{tabular}


The following two Hypotheses are advanced:

Hypothesis 1. Additional observations on a solution supplier's ability, integrity, and benevolence decrease customer's uncertainty about the supplier's solution.

Hypothesis 2. Additional observations on a solution supplier's ability, integrity, and benevolence increase customer's belief about the supplier's solution.

As belief, uncertainty, and disbelief sum to 1 , in this research we test only the first two of these three trust opinion values. It's not necessary to test the third opinion value.

Software comprised of three packages was developed.

The first package establishes a connection with a database created to store the research data.

The second package is a web-crawler used to collect data from the Eclipse Marketplace and save it to the database.

The third package uses trust network analysis with subjective logic (Jøsang et al., 2004 ) to calculate benchmark trust opinion values ( $\omega$-benchmark), and generates simulated observations on solution suppliers' ability, integrity, and benevolence.

After simulated observations are generated, trust opinion values are re-calculated $(\omega$ simulation). 
The simulated trust opinion values ( $\omega$-simulation) are compared to benchmark trust opinion values ( $\omega$-benchmark) to test Hypotheses 1 and 2, and answer the research question.

Table 5 shows how trust opinion values are compared to test Hypotheses 1 and 2.

Table 5: Test of hypotheses

\begin{tabular}{|l|c|c|}
\hline $\begin{array}{l}\text { Simulated observations on } \\
\text { solution supplier's: }\end{array}$ & $\begin{array}{c}\text { Uncertainty } \\
\text { value on }\end{array}$ & $\begin{array}{c}\text { Belief } \\
\text { value on }\end{array}$ \\
\hline Ability + Integrity + Benevolence & $\begin{array}{c}\mathrm{H} 2 \text { is rejected if } \\
(\omega \text {-simulation })\end{array}$ & $\begin{array}{c}(\omega \text {-simulation }) \\
<\end{array}$ \\
\hline
\end{tabular}

Table 5 shows that if the uncertainty value of the simulated trust opinion is higher than the uncertainty value of the benchmark trust opinion then Hypothesis 1 is rejected.

Hypothesis 1 is rejected because the uncertainty value (between 0 and 1 ) of a trust opinion should decrease when simulated observations on solution supplier's ability, integrity, and benevolence are added.

If the belief value of the simulated trust opinion values is lower than the belief value of benchmark trust opinion values then Hypothesis 2 is rejected. 
Hypothesis 2 is rejected because the belief value (between 0 and 1) of a trust opinion should increase when simulated observations on solution supplier's ability, integrity, and benevolence are added.

Figure 8 shows the relation between observations on the keystone, members, and solution suppliers and the calculation of trust opinion values in a transitive trust network.

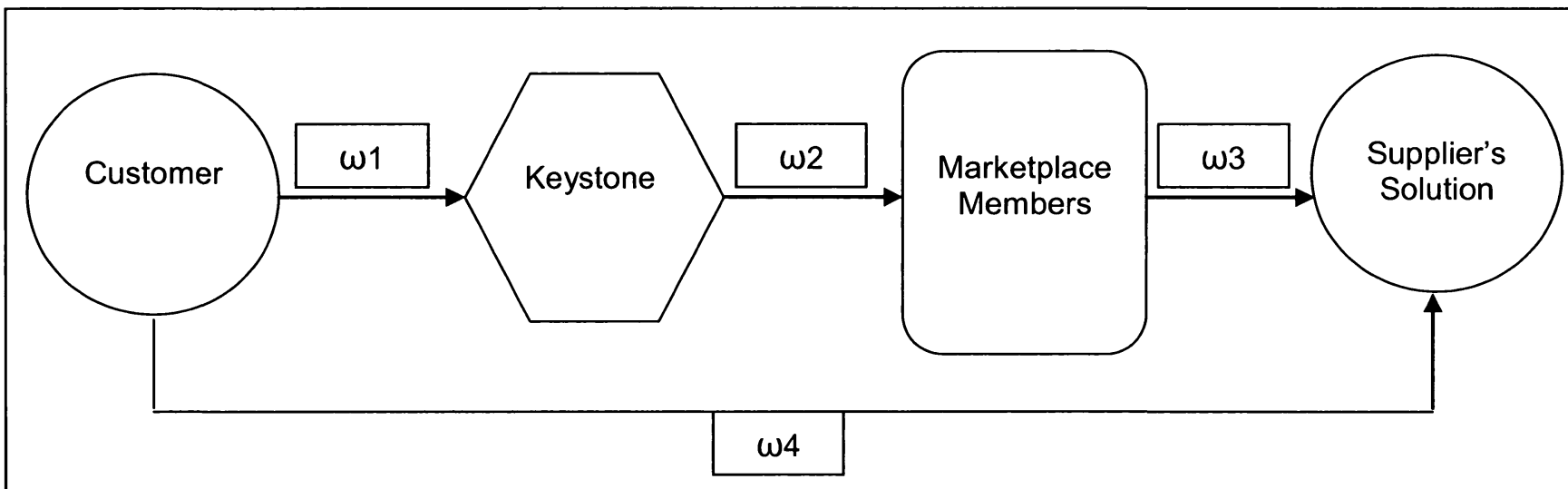

$\omega 1$ is computed based on observations on the keystone.

$\omega 2$ is computed based on observations on the marketplace members.

$\omega 3$ is computed based on observations on the supplier's solution.

$\omega 4$ is computed using TNA-SL to combine $\omega 1, \omega 2$ and $\omega 3$.

Figure 8: Relation between observations and trust opinion values ( $\omega)$

Figure 8 shows that the customer's opinion about the keystone $(\omega 1)$ has its trust opinion values (belief, disbelief, and uncertainty) calculated based on observations about the keystone. The keystone's opinion about the marketplace members ( $\omega 2)$ has its trust opinion values calculated based on observations about marketplace members. The marketplace members' opinions about a solution ( $\omega 3)$ have their trust opinion 
values calculated based on observations about the supplier's solution. In the indirect trust arc between the customer and the supplier's solution, the customer's opinion about the supplier's solution ( $\omega 4)$ is calculated using TNAL-SL to combine $\omega 1, \omega 2$, and $\omega 3$.

\subsubsection{Unit of analysis}

The unit of analysis is information on a solution published in the marketplace website operated by the Eclipse Foundation.

For each solution, the information collected is comprised of:

1. Solution name

2. Solution category

3. Indication of whether or not the solution is tagged with the Eclipse Foundation Member logo

4. List of members that selected the solution as their favourite

5. Reviews provided by members about the solution

\subsubsection{Source of data}

The source of data for this research is the Eclipse Marketplace website available at: http://marketplace.eclipse.org/.

\subsubsection{Time period}

Data was collected during the months of April and June of 2010. 


\subsubsection{Sample selection}

The solutions included in the sample were selected using three steps:

1. In the Eclipse Marketplace the solution categories that met the following criteria as of June, $21^{\text {st }} 2010$ were selected:

a) Contains at least 25 solutions and no more than 50 solutions

b) Contains more than one solution with a review provided by a marketplace member

c) Contains more than one solution placed in the list of favorite solutions of marketplace members

2. Randomly select two solution categories from the list of categories that fit the criteria defined on step 1.

3. For each of the two categories, select the first eight solutions identified within the marketplace website with the highest number of marketplace members that had selected the solution as their favourite.

Information about 16 solutions was collected ( 2 categories $\times 8$ solutions per category).

\subsection{Research steps}

Table 6 outlines the steps undertaken to complete this research. 
Table 6: Research steps

\begin{tabular}{|c|c|c|}
\hline Step & Dominant activity undertaken & Deliverable \\
\hline 1 Develop model & $\begin{array}{l}\text { Develop a trust model to test } \\
\text { Hypotheses } 1 \text { and } 2 \text { based on three } \\
\text { trust dimensions identified in the } \\
\text { literature review and trust network } \\
\text { analysis with subjective logic }\end{array}$ & Trust model \\
\hline $\begin{array}{l}2 \text { Operationalize } \\
\text { the model }\end{array}$ & $\begin{array}{l}\text { 2.1 Develop a database schema to } \\
\text { store information on the solutions } \\
\text { in the sample } \\
\text { 2.2 Develop a web-crawler to collect } \\
\text { information about the } 16 \text { solutions } \\
\text { in the sample } \\
\text { 2.3 Develop software to represent a } \\
\text { trust network and compute trust } \\
\text { opinion values (belief, disbelief, } \\
\text { and uncertainty) to use as } \\
\text { benchmarks. } \\
\text { 2.4 Develop software to generate } \\
\text { additional simulated observations } \\
\text { about solution supplier's ability, } \\
\text { integrity, and benevolence }\end{array}$ & $\begin{array}{l}\text { Details about the } \\
\text { operationalized model }\end{array}$ \\
\hline $\begin{array}{l}3 \text { Data } \\
\text { acquisition }\end{array}$ & $\begin{array}{l}\text { Acquire data following three steps: } \\
\text { 3.1 Select two solution categories to } \\
\text { collect data } \\
3.2 \text { Launch the web-crawler } \\
\text { developed on step } 2.2 \text { to collect } \\
\text { and store in a database } \\
\text { information about solutions } \\
\text { published in the Eclipse } \\
\text { Marketplace } \\
\text { 3.3 For each solution, code each } \\
\text { review published by a member as } \\
\text { positive, negative, or neutral } \\
\text { based on the content of the } \\
\text { review. }\end{array}$ & Database on solutions \\
\hline
\end{tabular}




\begin{tabular}{|c|c|c|}
\hline 4 Benchmark & $\begin{array}{l}\text { Execute software developed in step } \\
2.3 \text { to calculate benchmark trust } \\
\text { opinion values using data acquired } \\
\text { from step } 3.2 \text { and } 3.3\end{array}$ & $\begin{array}{l}\text { Table with benchmark } \\
\text { trust opinion values } \\
\text { (belief, disbelief, and } \\
\text { uncertainty) }\end{array}$ \\
\hline $\begin{array}{l}5 \text { Ability } \\
\text { Simulation }\end{array}$ & $\begin{array}{l}\text { 5.1 Execute software developed in } \\
\text { step } 2.4 \text { to generate additional } \\
\text { simulated observations pertinent } \\
\text { to a solution supplier's ability. } \\
5.2 \text { Execute software developed in } \\
\text { step } 2.3 \text { to re-calculate trust } \\
\text { opinion values using data acquired } \\
\text { from step } 3.2 \text { and } 3.3 \text { plus } \\
\text { simulated data generated on step } \\
5.1\end{array}$ & $\begin{array}{l}\text { Table with simulated trust } \\
\text { opinion values after } \\
\text { additional simulated } \\
\text { observations on solution } \\
\text { supplier's ability are } \\
\text { added to the database }\end{array}$ \\
\hline $\begin{array}{l}6 \text { Benevolence } \\
\text { Simulation }\end{array}$ & $\begin{array}{l}\text { 6.1 Execute software developed in } \\
\text { step } 2.4 \text { to generate additional } \\
\text { simulated observations pertinent } \\
\text { to a solution supplier's } \\
\text { benevolence. } \\
\text { 6.2 Execute software developed in } \\
\text { step } 2.3 \text { to re-calculate trust } \\
\text { opinion values using data acquired } \\
\text { from step } 3.2 \text { and } 3.3 \text { plus } \\
\text { simulated data generated on step } \\
6.1\end{array}$ & $\begin{array}{l}\text { Table with simulated trust } \\
\text { opinion values after } \\
\text { additional simulated } \\
\text { observations on solution } \\
\text { supplier's benevolence } \\
\text { are added to the } \\
\text { database }\end{array}$ \\
\hline $\begin{array}{l}7 \text { Integrity } \\
\text { Simulation }\end{array}$ & $\begin{array}{l}\text { 7.1 Execute software developed in } \\
\text { step } 2.4 \text { to generate additional } \\
\text { simulated observations pertinent } \\
\text { to a solution supplier's integrity. } \\
7.4 \text { Execute software developed in } \\
\text { step } 2.3 \text { to re-calculate trust } \\
\text { opinion values using data acquired } \\
\text { from step } 3.2 \text { and } 3.3 \text { plus } \\
\text { simulated data generated on step } \\
7.1\end{array}$ & $\begin{array}{l}\text { Table with simulated trust } \\
\text { opinion values after } \\
\text { additional simulated } \\
\text { observations on solution } \\
\text { supplier's integrity are } \\
\text { added to the database }\end{array}$ \\
\hline
\end{tabular}




\begin{tabular}{|l|l|l|}
\hline $\begin{array}{l}\text { 8 Combined } \\
\text { simulation }\end{array}$ & $\begin{array}{l}\text { Execute software developed in step } \\
2.3 \text { to re-calculate trust opinion values } \\
\text { using data acquired from step 3.2 and } \\
3.3 \text { plus simulated data generated on } \\
\text { steps 5.1, 6.1, and 7.1 (ability, integrity } \\
\text { and benevolence simulations) }\end{array}$ & $\begin{array}{l}\text { Table with simulated trust } \\
\text { opinion values combining } \\
\text { simulated observations } \\
\text { on solution supplier's } \\
\text { ability, integrity, and } \\
\text { benevolence }\end{array}$ \\
\hline $\begin{array}{l}\text { 9 Test } \\
\text { Hypotheses }\end{array}$ & $\begin{array}{l}\text { Compare trust opinion values belief } \\
\text { and uncertainty from the results of } \\
\text { simulations with the trust opinion } \\
\text { values belief and uncertainty of the } \\
\text { benchmark }\end{array}$ & $\begin{array}{l}\text { Compare results of } \\
\text { simulations with } \\
\text { benchmark }\end{array}$ \\
\hline
\end{tabular}

\subsubsection{Step 1 - Develop model}

A model to test Hypotheses 1 and 2 is developed. It uses three trust dimensions as independent variables (suppliers' ability, integrity, and benevolence) and two dependent variables (customer's uncertainty and belief about a supplier's solution).

The model posits that a higher number of observations of a solution supplier's ability, integrity, and benevolence (independent variables) decreases customer's uncertainty about the supplier's solution, and increases customer's belief about the same supplier's solution (dependent variables).

\subsubsection{Step 2 - Operationalize the model}

The model is operationalized by developing a database schema to store information about solutions and by implementing web crawler software to collect data from the Eclipse marketplace, compute trust opinions, and generate additional simulated observations. 


\subsubsection{Step 3 - Data acquisition}

The web-crawler is used to collect information on 16 solutions from two randomly selected solution categories. The list of solution categories is provided in Appendix D.

The following information is collected:

1. Solution name

2. Solution category

3. Indication of whether or not the solution is tagged or not with the Eclipse Foundation Member logo

4. List of members that selected the solution as their favourite

5. Reviews provided by members about the solution

Based on the information collected from the marketplace we infer observations that a customer can use to decide whether or not to trust solutions and members.

Observations were coded as positive, negative, or neutral.

Negative and positive observations were used to compute trust opinion values using TNA-SL. Neutral observations were not used.

Observations about solutions related to reviews provided by members were examined by the researcher and based on his judgement coded as positive, negative, or neutral 
The presence of the Eclipse Foundation Member logo (icon: associated with a solution was coded as a positive observation about the solution.

An observation about a member was coded as positive if the member publishes a comment and/or selects a solution as a favourite solution.

The submission of a solution to the Eclipse Marketplace is also considered as a positive observation.

\subsubsection{Step 4 - Benchmark}

The method to calculate trust opinions embodied in the software is executed providing a customer with parameterized a-priori trust value and the number of positive and negative observations about the keystone.

The software receives the following parameters: customer a-priori trust value (real number between 0 and 1 ) denoted (a), number of positive observations that the customer has about the keystone denoted ( $r$ ), number of negative observations that the customer has about the keystone denoted (s).

The initial trust that would be put in any member of the community in the absence of any positive and negative observations must be a number between 0 and 1 . We assume a default a-priori trust value of 0.5 , as it is the average value to represent initial trust. 
We assume that the member has at least one positive observation about the Eclipse Foundation (that could be the availability of the marketplace itself). And we assume that the member had no negative observations about the Eclipse Foundation.

The TNA-SL model uses subjective logic probability and it doesn't rely on Bayesian probability recommendations for parameter sensitivity or confidence interval determination. The parameters were defined by inference based on the facts assumed about the Eclipse Foundation and the members.

Therefore the initial parameters to run the software are:

$$
\begin{aligned}
& a=0.5 \\
& r=1 \\
& s=0
\end{aligned}
$$

The software is then launched using data acquired from Eclipse Marketplace. Benchmark trust opinion values (belief, disbelief, and uncertainty) are returned for all solutions collected by the web-crawler and stored in the database.

After the benchmark execution of the software, the software methods to generate additional simulated observations pertinent to a solution supplier's ability, integrity, and benevolence are executed.

Two simulation passes were performed. The first pass was performed with solutions from category \#1. The second pass was performed with solutions from category \#2. The second pass was used to corroborate the findings of the first pass. 


\subsubsection{Step 5 - Ability simulation}

To provide additional observations about a solution supplier's ability, we simulate a system where members are invited to rate the solution with 1, 2, or 3 stars. One star means that the solution is not able to deliver what is promised, two stars means that the solution delivers what is promised with an average performance as any other solution; three stars means that the solution delivers what is promised better than average.

For a member that had reviewed a solution the simulation rates as:

- 1 star if the member had provided negative feedback about the solution.

- 2 or 3 stars if the member had provided positive feedback about the solution.

For a member that had selected a solution as favourite, the simulation randomly assigns 2 or 3 stars.

If the same member had provided a review and also selected the solution as favourite the simulation assigns a single random rate of 2 or 3 stars.

A simulated 1 star is considered as a negative observation.

A simulated 2 stars is considered as a neutral observation and is not computed.

A simulated 3 stars is considered as a positive observation. 


\subsubsection{Step 6 - Benevolence simulation}

A benevolent behavior of a solution supplier can be verified by the level of engagement it has with the community and on how much information it shares without expecting anything in return.

In order to simulate observations about the benevolence of a solution supplier we assume that the keystone provides them with a space in the marketplace where they can share free whitepapers with relevant content about their expertise with the community members. The greater the number of whitepapers they share, the more benevolent they are. The simulation randomly generates an integer number between 0 and 2 for the simulated number of whitepapers of each solution supplier.

A simulated number of 0 whitepapers is considered as a negative observation.

A simulated number of 1 or 2 whitepapers is considered as a positive observation.

\subsubsection{Step 7 - Integrity simulation}

Integrity is derived from the perception that the solution supplier adheres to a set of common accepted principles. The main source of observations for such behaviour relies on the reviews provided by other users. For the purpose of this simulation we add observations about integrity that are derived from an hypothetical "Integrity Seal" awarded by the Keystone to selected solutions suppliers that had hypothetically 
followed a set of established norms and principles. The simulation randomly applies the "Integrity Seal" to $25 \%$ of the solution suppliers.

The simulated presence of an "Integrity Seal" is considered as a positive observation.

\subsubsection{Step 8 - Combined simulation}

After the additional simulated observations on a solution supplier's ability, integrity, and benevolence are generated, the simulation software is re-executed to re-calculate trust opinion values using data acquired from Eclipse Marketplace plus simulated data that were generated. Updated trust opinion values (belief, disbelief, and uncertainty) are returned for all solutions collected by the web-crawler and stored in the database. 


\section{BENCHMARK, SIMULATIONS, AND RESULTS}

This chapter is divided into six sections. Section 4.1 presents the trust research model developed. Section 4.2 describes the implementation of the software to calculate the benchmark trust opinion values and generate simulated observations. Section 4.3 describes the data collection. Section 4.4 describes the software execution to calculate the benchmark trust opinion values. Section 4.5 describes the software execution to generate the simulations. Section 4.6 compares the simulations' results with the benchmark results.

\subsection{Step 1 - Develop model}

Table 7 illustrates the trust research model used to test Hypotheses 1 and 2.

Table 7: Trust research model

\begin{tabular}{|l|c|c|}
\hline \multirow{2}{*}{$\begin{array}{l}\text { Additional observations on } \\
\text { solution supplier's: }\end{array}$} & $\begin{array}{c}\text { Customer's trust opinion ( } \omega \text { ) about } \\
\text { supplier's solution }\end{array}$ \\
\cline { 2 - 3 } & $\begin{array}{c}\text { Uncertainty } \\
\text { value on } \\
\omega \text {-simulation } \\
\text { in relation to } \\
\omega \text {-benchmark }\end{array}$ & $\begin{array}{c}\text { Belief value on } \\
\omega \text {-simulation } \\
\text { in relation to } \\
\omega \text {-benchmark }\end{array}$ \\
\hline $\begin{array}{l}\text { +Ability } \\
\text { +Integrity } \\
\text { +Benevolence }\end{array}$ & - & \\
\hline
\end{tabular}


In Table 7 the independent variables are observations on solution supplier's ability, integrity, and benevolence. The dependent variables are customer's belief and uncertainty about a supplier's solution.

We expect that adding observations on solution supplier's ability, integrity, and benevolence decreases customer uncertainty about a supplier's solution and increases customer belief on a supplier's solution.

\subsection{Step 2 - Operationalize the model}

In this step we create the database to store information about solutions, develop the trust model software containing a web-crawler to collect data from selected solution categories of the Eclipse Foundation Marketplace website, implement classes to represent a trust network and compute trust opinion values, and implement methods to generate additional simulated observations about solution suppliers.

\subsubsection{Trust model software packages}

The software consists of three main packages: 1. a database wrapper; 2. a web-crawler to collect the data; and 3. a set of classes to a) represent the trust network and compute trust opinion values, and b) generate additional simulated data about observations on solution suppliers.

Table 8 describes the classes implemented in the software. 
Table 8: Classes implemented in the software

\begin{tabular}{|l|l|}
\hline Package 1: trustmodel.db & Description \\
\hline Class & $\begin{array}{l}\text { Class to establish the connection with database used to } \\
\text { store data collected by the web-crawler from the Eclipse } \\
\text { marketplace. It is used by other classes to perform insert, } \\
\text { update, and delete operations in the database Tables. }\end{array}$ \\
\hline Package 2: trustmodel.util & \multicolumn{2}{|l|}{ Description } \\
\hline Class & $\begin{array}{l}\text { Class to collect data from Eclipse marketplace (web- } \\
\text { crawler) }\end{array}$ \\
\hline Web.java & \multicolumn{2}{|l|}{} \\
\hline Package 3: trustmodel.trust & Description \\
\hline Class & $\begin{array}{l}\text { Class to represent and compute trust opinion values on } \\
\text { direct and indirect trust paths }\end{array}$ \\
\hline Arc.java & Class to represent indirect trust paths \\
\hline IndirectArc.java & $\begin{array}{l}\text { Class to represent the parties involved in the trust } \\
\text { network }\end{array}$ \\
\hline Nodes.java & Class to represent observations about the trust parties \\
\hline Observation.java & Class to represent trust opinions \\
\hline Opinion.java & Class to represent the scope of the trust network \\
\hline Scope.java & \multicolumn{2}{|l}{} \\
\hline
\end{tabular}

\subsubsection{Database schema}

A database schema is created to store the information about solutions retrieved from the marketplace. 
Table 9 describes the database Tables used by the classes implemented in the simulation software.

Table 9: Database tables used to collect and analyze data

\begin{tabular}{|l|l|}
\hline Database Table & Description \\
\hline Directarcs & Arcs from direct trust paths collected from Eclipse marketplace \\
\hline Indirectarcs & Arcs from indirect trust paths collected from Eclipse marketplace \\
\hline Nodes & All trust parties involved in the Eclipse marketplace trust network \\
\hline Observations & Observations collected from Eclipse marketplace \\
\hline Scope & Scope of solutions collected from Eclipse marketplace \\
\hline Variants & $\begin{array}{l}\text { Scope variants of trust arcs (customer, keystone, reviewer, or } \\
\text { solution) }\end{array}$ \\
\hline
\end{tabular}

The first package implemented in the software makes the database available to the simulation through the wrapper class.

\subsubsection{Web-crawler}

Package 2 has a web-crawler developed to browse the Eclipse Marketplace website and list all solution categories available. The researcher is then able to select categories to collect data. The crawler reads and interprets HTML content from the URL http://marketplace.eclipse.org looking for information about the solutions of the selected categories, finds the information and saves the collected data to a set of tables in the database connected with the first package.

The following entries are considered as valid observations and collected by the webcrawler: reviews from members about solutions; list of members that have put the solutions in their favourites list; solutions tagged with Eclipse Foundation Member icon. 
The observations are coded as positive, negative, and neutral as outlined in section 3.3.3 Step 3 - Data acquisition.

Table 10 describes the main methods of the class Web.java (methods' parameters were omitted):

Table 10: Methods implemented in the class Web.java

\begin{tabular}{|l|l|}
\hline Method & Description \\
\hline getComments() & $\begin{array}{l}\text { Reads comments made by marketplace members } \\
\text { about a given solution }\end{array}$ \\
\hline getSolutions() & $\begin{array}{l}\text { Reads a list of solutions available on the } \\
\text { marketplace for a given scope }\end{array}$ \\
\hline getSolutionDetails() & $\begin{array}{l}\text { Reads the details about a given solution and get the } \\
\text { list of members that had selected the solution as } \\
\text { their favourite }\end{array}$ \\
\hline loadPage() & $\begin{array}{l}\text { Reads the html content from a page of the } \\
\text { marketplace website (crawler) }\end{array}$ \\
\hline recordNode() & $\begin{array}{l}\text { Stores information about a member or solution in the } \\
\text { database }\end{array}$ \\
\hline recordTrustArc() & $\begin{array}{l}\text { Stores information about the trust relationship } \\
\text { between members and solutions in the database }\end{array}$ \\
\hline
\end{tabular}

\subsubsection{Trust network representation and computation of trust opinion values}

The class Arc.java is used to represent and compute trust opinion values for all direct and indirect arcs of the trust paths between the customer and the solution. It is used to calculate benchmark trust opinion values and it is also used to calculate simulated trust opinion values after the additional simulated observations are added to the database. 
Table 11 describes the main methods of the class Arc.java:

Table 11: Methods implemented in the class Arc.java

\begin{tabular}{|l|l|}
\hline Method & Description \\
\hline buildTransitiveTrustNetwork() & $\begin{array}{l}\text { Reads and computes all trust arcs collected by the } \\
\text { web crawler to build the transitive trust network } \\
\text { canonical expressions }\end{array}$ \\
\hline calcConsensus(List of Arcs) & $\begin{array}{l}\text { Performs a consensus calculation of a given list of } \\
\text { trust arcs }\end{array}$ \\
\hline calcDiscounting(List of Arcs) & $\begin{array}{l}\text { Performs a discounting calculation of a given list of } \\
\text { trust arcs }\end{array}$ \\
\hline
\end{tabular}

In this research we use a slightly modified version of the notation proposed by Jøsang et al. (2006) to represent a transitive trust network. This notation is described in Appendices A and B.

Appendix A describes the notation used in the software to express trust arcs and trust paths.

Appendix B describes the notation used in the software to express and calculate trust opinions.

Appendix $\mathrm{C}$ describes the notation and formulas used to represent and calculate discounting and consensus.

The method buildTransitiveTrustNetwork() of the class Arc.java uses the notation outlined in appendices $A$ and $B$ to generate a representation of all trust arcs involved in 
the trust path between the customer and each solution, and uses the formulas presented in appendix $\mathrm{C}$ to compute trust opinion values for each trust arc.

The method buildTransitiveTrustNetwork() is first executed using data collected from Eclipse marketplace before additional simulated observations are added to the database to calculate benchmark trust opinion values. It is re-executed later, after the ability, integrity, and benevolence simulations, to calculate the simulated trust opinion values.

The method buildTransitiveTrustNetwork() generates trust paths and computes trust opinion values for the following direct and indirect trust arcs:

a) Direct trust arc between customer and the keystone: [customer, keystonecode, dr.KEY.scope-code]

b) Direct trust arc between keystone and members: [keystone-code, membercode, dr.REV.scope-code]

c) Direct trust arc between a member and a solution: [member-code, solutioncode, df.SOL.scope-code]

d) Direct trust arc between the keystone and a solution: [keystone-code, solution- code, df.SOL.scope-code]

e) Indirect trust arc between the keystone and a solution: [keystone-code, solution- code, if.SOL.scope-code]

f) Indirect trust arc between customer and solution: [customer, solution-code, if.SOL.scope-code] 
Table 12 describes the scope variants used in the representation of the trust arcs.

Table 12: Scope variants used to build the transitive trust network

\begin{tabular}{|l|l|}
\hline Scope variant & Description \\
\hline dr.KEY & Direct referral trust in a keystone \\
\hline dr.REV & Direct referral trust in a reviewer (marketplace member) \\
\hline df.SOL & Direct functional trust in a solution \\
\hline if.SOL & Indirect functional trust in a solution \\
\hline
\end{tabular}

Figure 9 presents the formula using TNA-SL to achieve the final customer's trust opinion values about a solution.

$\omega$ [customer, solution-code, if.SOL.scope-code] $=$

$\omega[$ customer, keystone-code, dr.KEY.scope-code] $\otimes$

[ $\omega[$ keystone-code, solution-code, df.SOL.scope-code] $\oplus$

( $\omega[$ keystone-code, member-code, dr.REV.scope-code $] \otimes$

( $\omega\left[\right.$ member $_{1}$-code, solution- code, df.SOL.scope-code $] \oplus$

$\omega\left[\right.$ member $_{\mathrm{n}}$-code, solution- code, df.SOL.scope-code]))]

\section{Figure 9: Customer's trust opinion values formula}

The trust opinion values in each direct trust arc are computed based on the number of positive ( $r$ ) and negative (s) observations from the truster about the trustee. 
Table 13 shows how the parameters $r$ and $s$ are defined for each different type of direct trust arc on the calculation of the benchmark trust opinion values and simulated trust opinion values.

Table 13: Parameters $r$ and $s$ used for trust opinion values calculation

\begin{tabular}{|c|c|c|}
\hline \multirow[t]{2}{*}{ Direct trust arc } & \multicolumn{2}{|c|}{$\begin{array}{l}\text { Parameters to calculate benchmark trust opinion } \\
\text { values }\end{array}$} \\
\hline & $r$ & $\mathrm{~s}$ \\
\hline [customer, keystone] & $\begin{array}{l}\text { Manually entered as a } \\
\text { software parameter. } \\
\text { Default }=1\end{array}$ & $\begin{array}{l}\text { Manually entered as a } \\
\text { software parameter. } \\
\text { Default = } 0\end{array}$ \\
\hline [keystone, solution] & $\begin{array}{l}\text { Based on: } \\
\text { 1. Submission of a solution } \\
\text { 2. Presence of Eclipse } \\
\text { Foundation Member logo }\end{array}$ & Default $=0$ \\
\hline [keystone, member] & $\begin{array}{l}\text { Based on: } \\
\text { 1. Member activity on the } \\
\text { marketplace }\end{array}$ & Default $=0$ \\
\hline [member, solution] & $\begin{array}{l}\text { Based on: } \\
\text { 1. Content of reviews } \\
\text { submitted by members } \\
\text { coded as positive } \\
\text { 2. List of members that had } \\
\text { selected the solution as } \\
\text { their favourite }\end{array}$ & $\begin{array}{l}\text { Based on: } \\
\text { 1. Content of reviews } \\
\text { submitted by members } \\
\text { coded as negative }\end{array}$ \\
\hline \multirow[t]{2}{*}{ Direct trust arc } & \multicolumn{2}{|c|}{$\begin{array}{l}\text { Parameters to calculate simulated trust opinion } \\
\text { values }\end{array}$} \\
\hline & $r$ & $\mathrm{~s}$ \\
\hline [customer, keystone] & Same as benchmark & Same as benchmark \\
\hline [keystone, solution] & $\begin{array}{l}\text { Same as benchmark plus } \\
\text { simulated observations }\end{array}$ & $\begin{array}{l}\text { Same as benchmark plus } \\
\text { simulated observations }\end{array}$ \\
\hline [keystone, member] & Same as benchmark & Same as benchmark \\
\hline [member, solution] & $\begin{array}{l}\text { Same as benchmark plus } \\
\text { simulated observations }\end{array}$ & $\begin{array}{l}\text { Same as benchmark plus } \\
\text { simulated observations }\end{array}$ \\
\hline
\end{tabular}


Table 13 shows that for the direct trust arc between the customer and the keystone, the parameters $r$ and $s$ are manually entered at the moment of the software execution. To calculate the benchmark and simulated trust opinion values we considered that the customer had at least one positive observation about the keystone and no negative observations.

For the direct trust arc between the keystone and the solution, the parameter $r$ is defined based on the presence or not of the Eclipse Foundation logo on the solution's listing in the marketplace. The submission of the solution to the marketplace is also considered as a positive observation, which is made to consider that the keystone has at least one positive observation about the solution. Additional positive and negative observations from the keystone about the solutions are generated by the simulation and used to calculate simulated trust opinion values.

For the direct trust arc between keystone and members, the parameter $r$ is defined based on the activity of the member within the marketplace. Each feedback provided by the member (reviews and selection of solutions as favorites) is considered as a positive observation about the member. No negative observations were collected or simulated about members.

For the direct trust arc between the member and the solution, the parameters $r$ and $s$ are defined based on the content of reviews provided by members and on the number of members that had selected the solution as their favorite. Reviews are considered as positive, negative, or neutral based on the judgement of the researcher. The selection of the solution as favorite by member is considered as a positive observation about the 
solution. Additional positive and negative observations from the member about the solutions are generated by the simulation used to calculate simulated trust opinion values.

Section 4.2.5 describes how the additional simulated observations are generated.

The trust opinion values of the indirect trust arcs between customer, keystone, and solution are computed based on discounting and consensus of the trust opinion values of the direct trust arcs in the trust path as shown in figure 11.

The final result of the operations performed by buildTransitiveTrustNetwork() is the customer's trust opinion values comprising belief, disbelief, and uncertainty about each solution.

The output of buildTransitiveTrustNetwork() method for each solution is displayed using a template described in appendix $\mathrm{J}$.

\subsubsection{Generate simulated observations}

The class Observation.java is used to represent observations about solutions and members, count the number of positive and negative observations, and generate simulated observations.

Table 14 describes the main methods of the class Observation.java: 
Table 14: Methods implemented in the class Observation.java

\begin{tabular}{|l|l|}
\hline Method & Description \\
\hline countRS() & $\begin{array}{l}\text { Counts the number of positive }(r) \text { and negative (s) } \\
\text { observations about a given solution or member }\end{array}$ \\
\hline getObsbyArc() & Reads all observations related to a given trust arc \\
\hline simulateAbility() & $\begin{array}{l}\text { Generates simulated observations about a solution } \\
\text { supplier's ability as outlined in section 3.3.5 }\end{array}$ \\
\hline simulateBenevolence() & $\begin{array}{l}\text { Generates simulated observations about a solution } \\
\text { supplier's benevolence as outlined in section 3.3.6 }\end{array}$ \\
\hline simulateIntegrity() & $\begin{array}{l}\text { Generates simulated observations about a solution } \\
\text { supplier's integrity as outlined in section 3.3.7 }\end{array}$ \\
\hline
\end{tabular}

After executing the methods simulateAbility(), simulateBenevolence(), and simulatelntegrity() of the class Observation.java, the researcher is then able to reexecute buildTransitiveTrustNetwork() method of the class Arc.java to analyze the impact of the simulation on the customer's trust opinion values.

\subsection{Step 3 - Data acquisition}

The web.java class (web-crawler) is executed to collect information about solutions from the Eclipse Marketplace from two selected categories denoted Documentation and Team development.

Figure 10 shows that the Eclipse Marketplace website provided information on 1,000 solutions as of June 12, 2010. 
to it marketplace eclopse org

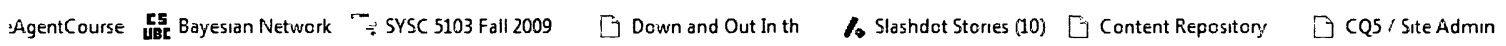

marketplace

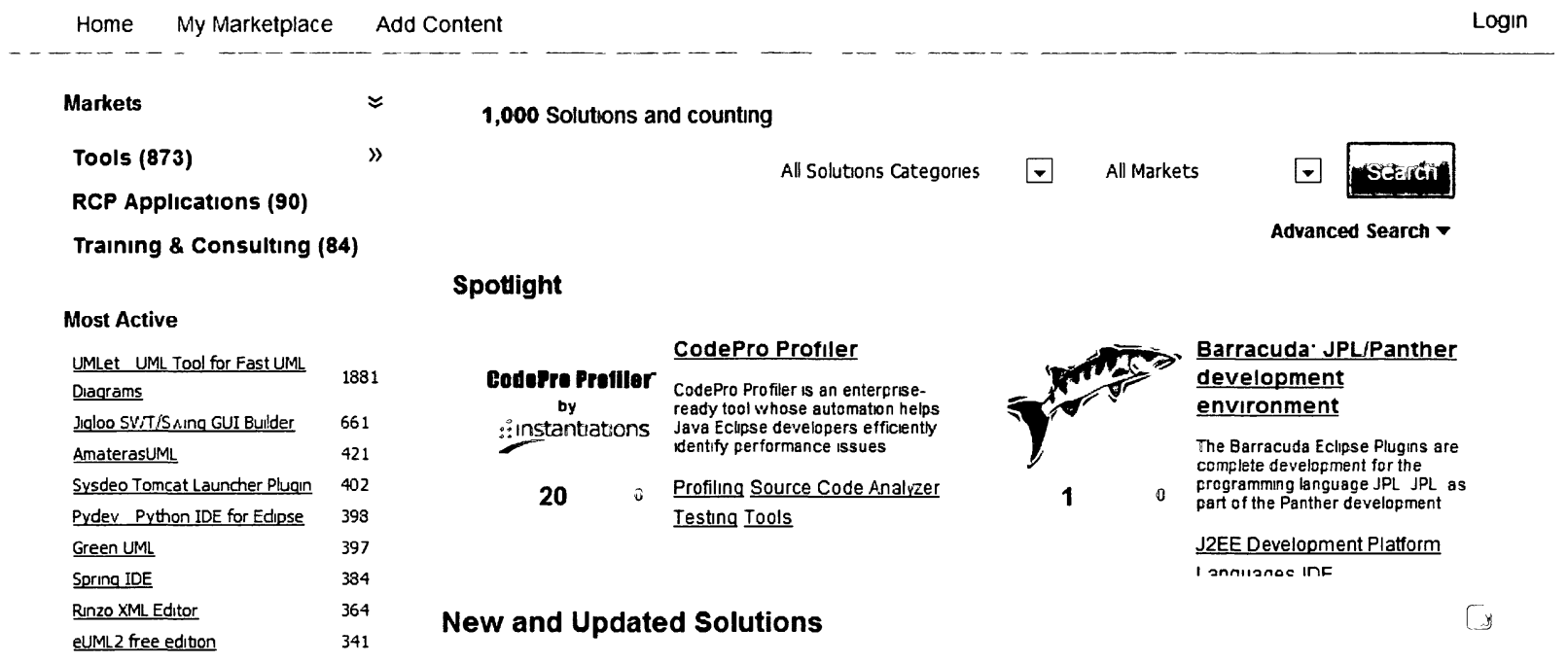

\section{Figure 10: Eclipse Marketplace}

Table 15 list the top 8 solutions with most observations acquired from category

"Documentation" (scope code S5).

Table 15: List of top 8 solutions with the most observations - scope S5

\begin{tabular}{|l|l|}
\hline SolutionCode & \# observations \\
\hline umlet-uml-tool-fast-uml-diagrams & 60 \\
\hline Wireframesketcher & 30 \\
\hline rcp-developer & 18 \\
\hline mylyn-wikitext & 15 \\
\hline Jautodoc & 7 \\
\hline Eclox & 6 \\
\hline Jdoceditor & 5 \\
\hline Texlipse & 5 \\
\hline
\end{tabular}


Table 16 list the top 8 solutions with most observations acquired from category "Team Development" (scope code S15).

Table 16: List of top 8 solutions with most observations - scope S15

\begin{tabular}{|l|l|}
\hline SolutionCode & \# observations \\
\hline Subclipse & 52 \\
\hline subversive-svn-team-provider & 29 \\
\hline mercurialeclipse-was-hgeclipse & 24 \\
\hline $\begin{array}{l}\text { pulse-download-manage-and-maintain-eclipse- } \\
\text { tools }\end{array}$ & 21 \\
\hline atlassian-connector-eclipse & 15 \\
\hline collabnet-desktop-eclipse-edition & 6 \\
\hline amazon-s3-browser & 3 \\
\hline mintjams-content-management & 3 \\
\hline
\end{tabular}

In total 321 observations about the 16 solutions were inferred from the data collected from Eclipse Marketplace involving: the submission of the 16 solutions; 18 solution reviews by marketplace members; 282 selections of solutions as favourite by marketplace members; 5 solutions tagged with the Eclipse Foundation member logo.

The solution reviews by marketplace members (18 in total) were individually analysed to be considered as positive, negative, or neutral. All the other observations about solutions were by default considered as positive.

Figure 11 displays examples of reviews retrieved from the Eclipse Marketplace website. 


\section{T. Reviews}

4udu a Fe, Ien

Posted on 19/03/2010

By KAPI

\section{WireFrameSketcher is really useful}

We are workıng on WebApps desıgn and devlopment We were used to sketch our future screens on basıc tool such as a PowerPoint-lıke application We tried WireframeSketcher to design a new service for SmartPhones and we were pleasantly surprised that was fine $I$ even for SmartPhones screens design And it is really convenient since we dont have to get off Eclipse

Good Job, we recommend it I

Login or reqıster to post comments

\section{Posted on 06/03/2010 Great Prototyping Plugin}

By hoffmanut

Really great tool IVe tried several prototyping tools, such as Balsamıq Mockups, Axure RP or Mockup Screens and my favorite was Balsamıq Mockups But WireframeSketcher is a must-have plugın for everyone who works with Eclipse

Many thanks!

Loqin or requster to post comments

\section{Figure 11: Example of reviews in Eclipse Marketplace}

Figure 12 displays a list of members that had selected a specific as their favourite.

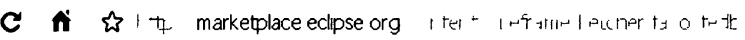

\section{marketplace}

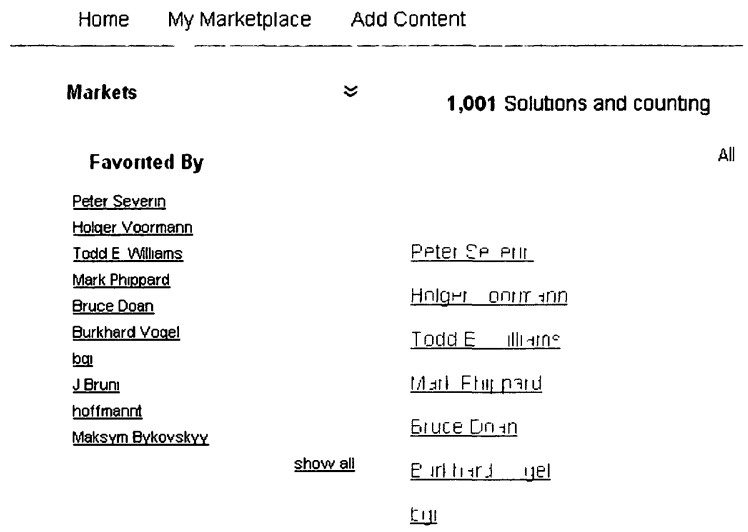

Figure 12: Example of a list of members that have "favorited" a solution 


\subsection{Benchmark and simulations}

The software is executed for three purposes: 1. calculate benchmark trust opinion values; 2 . generate simulated observations; and 3. calculate simulated trust opinion values.

\subsubsection{Step 4 - Benchmark calculation}

The software class to build the transitive trust network with subjective logic (method buildTransitiveTrustNetwork() of the class Arc.java) is executed to generate a representation of all transitive trust paths for each solution followed by all necessary calculus that result in the final trust opinion values for the main trust arc: [customer, solution, if.scope].

The benchmark execution is performed without any additional simulated observations on the database but using only observations collected from the Eclipse Marketplace website.

The result of this execution is exemplified on appendix $\mathrm{H}$ with the solution code 'texlipse'.

Figure 13 displays how the parameters are passed to the software. 


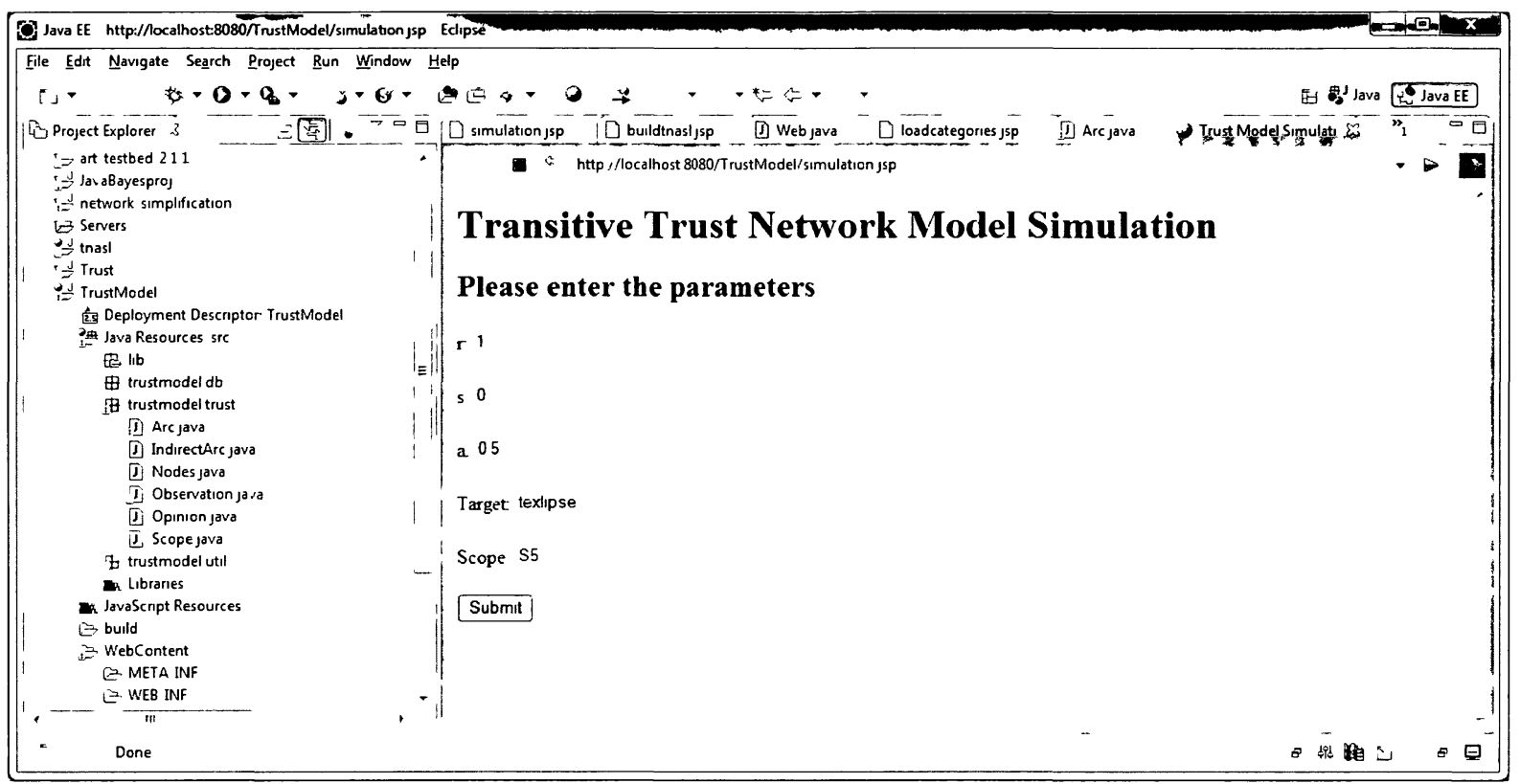

\section{Figure 13: Execution of the software}

The output of this benchmark execution for the solution 'texlipse' is displayed on appendix G.

\subsubsection{Benchmark results}

The initial results for the customer's trust opinion on this benchmark calculation execution for all 16 solutions (eight from each category) using observations collected from the marketplace and not adding any simulated observations are displayed in Table 16.

By comparing the benchmark results on Table 17 with the output of the simulations it will be possible to identify whether the simulated observations on a solution supplier's ability, integrity, and benevolence will increase belief and decrease uncertainty. 
Table 17: Benchmark results using only observation from the marketplace website

\begin{tabular}{|c|c|c|c|c|}
\hline \multirow[b]{2}{*}{ Solution Code } & \multirow[b]{2}{*}{$\begin{array}{l}\text { Scope } \\
\text { Code }\end{array}$} & \multicolumn{3}{|c|}{ Customer's trust opinion values about the solution } \\
\hline & & Belief & Disbelief & Uncertainty \\
\hline $\begin{array}{l}\text { umlet-uml-tool- } \\
\text { fast-uml-diagrams }\end{array}$ & S5 & 0.293475051668142 & 0.00442869796279893 & 0.702096250369058 \\
\hline wireframesketcher & S5 & 0.273453093812375 & 0 & 0.726546906187625 \\
\hline rcp-developer & S5 & 0.261261261261261 & 0 & 0.738738738738739 \\
\hline mylyn-wikitext & S5 & 0.260869565217391 & 0 & 0.739130434782609 \\
\hline Jautodoc & S5 & 0.211009174311926 & 0 & 0.788990825688073 \\
\hline Eclox & S5 & 0.198653198653198 & 0 & 0.801346801346801 \\
\hline jdoceditor & S5 & 0.194444444444444 & 0 & 0.8055555555555556 \\
\hline Texlipse & S5 & 0.182389937106918 & 0 & 0.817610062893082 \\
\hline Subclipse & S15 & 0.296650508755841 & 0 & 0.703349491244159 \\
\hline $\begin{array}{l}\text { subversive-svn- } \\
\text { team-provider }\end{array}$ & $\mathrm{S} 15$ & 0.277310924369748 & 0 & 0.722689075630252 \\
\hline $\begin{array}{l}\text { mercurialeclipse- } \\
\text { was-hgeclipse }\end{array}$ & S15 & 0.267326732673267 & 0 & 0.732673267326733 \\
\hline $\begin{array}{l}\text { pulse-download- } \\
\text { manage-and- } \\
\text { maintain-eclipse- } \\
\text { tools }\end{array}$ & $\mathrm{S} 15$ & 0.26241134751773 & 0 & 0.73758865248227 \\
\hline $\begin{array}{l}\text { atlassian- } \\
\text { connector-eclipse }\end{array}$ & S15 & 0.244444444444444 & 0 & 0.755555555555556 \\
\hline $\begin{array}{l}\text { collabnet-desktop- } \\
\text { eclipse-edition }\end{array}$ & S15 & 0.221288515406162 & 0 & 0.778711484593837 \\
\hline amazon-s3-browser & S15 & 0.168724279835391 & 0 & 0.831275720164609 \\
\hline $\begin{array}{l}\text { mintjams-content- } \\
\text { management }\end{array}$ & S15 & 0.168724279835391 & 0 & 0.831275720164609 \\
\hline
\end{tabular}

\subsubsection{Generation of simulated observations}

In the second round of execution we added simulated observations about the solution

supplier's ability, integrity, and benevolence as outlined in sections 3.3.4.2, 3.3.4.3, and 3.3.4.4. 


\subsubsection{Step 5 - Ability simulation}

The method simulateAbility() of the class observation.java was used to generate simulated observations on solution supplier's ability. The simulated observations were generated as described in section 3.3.4.2 Ability.

The simulated trust opinion values resulted after the use of the method simulateAbility() are displayed in Table 18.

Table 18: Simulation results with simulated observations about the solution supplier's ability

\begin{tabular}{|c|c|c|c|c|}
\hline \multirow[b]{2}{*}{ Solution Code } & \multirow[b]{2}{*}{$\begin{array}{l}\text { Scope } \\
\text { Code }\end{array}$} & \multicolumn{3}{|c|}{ Simulated trust opinion values about the solution } \\
\hline & & Belief & Disbelief & Uncertainty \\
\hline $\begin{array}{l}\text { umlet-uml-tool- } \\
\text { fast-uml-diagrams }\end{array}$ & S5 & 0.299200866856291 & 0.00568874441284031 & 0.695110388730868 \\
\hline wireframesketcher & S5 & 0.284098235742336 & 0 & 0.715901764257664 \\
\hline rep-developer & S5 & 0.274509803921568 & 0 & 0.725490196078431 \\
\hline mylyn-wikitext & S5 & 0.275145469659185 & 0 & 0.724854530340815 \\
\hline jautodoc & S5 & 0.229706390328152 & 0 & 0.770293609671848 \\
\hline Eclox & S5 & 0.211752786220871 & 0 & 0.788247213779129 \\
\hline jdoceditor & S5 & 0.211752786220871 & 0 & 0.788247213779129 \\
\hline Texlipse & S5 & 0.191990577149588 & 0 & 0.808009422850412 \\
\hline subclipse & S15 & 0.302842208428618 & 0 & 0.697157791571382 \\
\hline $\begin{array}{l}\text { subversive-svn- } \\
\text { team-provider }\end{array}$ & S15 & 0.283889575607746 & 0 & 0.716110424392254 \\
\hline $\begin{array}{l}\text { mercurialeclipse- } \\
\text { was-hgeclipse }\end{array}$ & S15 & 0.281182094741417 & 0 & 0.718817905258583 \\
\hline $\begin{array}{l}\text { pulse-download- } \\
\text { manage-and- } \\
\text { maintain-eclipse- } \\
\text { tools }\end{array}$ & S15 & 0.270440251572327 & 0 & 0.729559748427673 \\
\hline $\begin{array}{l}\text { atlassian- } \\
\text { connector-eclipse }\end{array}$ & S15 & 0.262032085561497 & 0 & 0.737967914438503 \\
\hline $\begin{array}{l}\text { collabnet-desktop- } \\
\text { eclipse-edition }\end{array}$ & S15 & 0.237179487179487 & 0 & 0.762820512820513 \\
\hline amazon-s3-browser & S15 & 0.18407960199005 & 0 & 0.81592039800995 \\
\hline $\begin{array}{l}\text { mintjams-content- } \\
\text { management }\end{array}$ & S15 & 0.178893178893179 & 0 & 0.821106821106821 \\
\hline
\end{tabular}




\subsubsection{Step 6 - Benevolence simulation}

The method simulateBenevolence() of the class observation.java was used to generate simulated observations on solution supplier's benevolence. The simulate observations were generated as described in section 3.3.4.3 Benevolence.

The simulated trust opinion values resulted after the use of the method simulateBenevolence () are displayed in Table 19.

Table 19: Simulation results with simulated observations about solution suppliers' benevolence

\begin{tabular}{|c|c|c|c|c|}
\hline \multirow[b]{2}{*}{ Solution Code } & \multirow[b]{2}{*}{$\begin{array}{l}\text { Scope } \\
\text { Code }\end{array}$} & \multicolumn{3}{|c|}{ Simulated trust opinion values about the solution } \\
\hline & & Belief & Disbelief & Uncertainty \\
\hline $\begin{array}{l}\text { umlet-uml-tool- } \\
\text { fast-uml-diagrams }\end{array}$ & S5 & 0.295486403139893 & 0.00420521446593775 & 0.700308382394169 \\
\hline wireframesketcher & S5 & 0.250915750915751 & 0.0274725274725275 & 0.721611721611722 \\
\hline rcp-developer & S5 & 0.268292682926829 & 0 & 0.731707317073171 \\
\hline mylyn-wikitext & S5 & 0.26797385620915 & 0 & 0.73202614379085 \\
\hline jautodoc & S5 & 0.178294573643411 & 0.0516795865633075 & 0.770025839793282 \\
\hline Eclox & S5 & 0.165266106442577 & 0.0560224089635855 & 0.778711484593837 \\
\hline jdoceditor & S5 & 0.218390804597701 & 0 & 0.781609195402299 \\
\hline Texlipse & S5 & 0.21025641025641 & 0 & 0.78974358974359 \\
\hline subclipse & S15 & 0.298563682271617 & 0 & 0.701436317728383 \\
\hline $\begin{array}{l}\text { subversive-svn- } \\
\text { team-provider }\end{array}$ & S15 & 0.281653746770026 & 0 & 0.718346253229974 \\
\hline $\begin{array}{l}\text { mercurialeclipse- } \\
\text { was-hgeclipse }\end{array}$ & S15 & 0.273273273273273 & 0 & 0.726726726726727 \\
\hline $\begin{array}{l}\text { pulse-download- } \\
\text { manage-and- } \\
\text { maintain-eclipse- } \\
\text { tools }\end{array}$ & S15 & 0.237179487179487 & 0.0320512820512821 & 0.730769230769231 \\
\hline $\begin{array}{l}\text { atlassian- } \\
\text { connector-eclipse }\end{array}$ & S15 & 0.215686274509804 & 0.0392156862745098 & 0.745098039215686 \\
\hline $\begin{array}{l}\text { collabnet-desktop- } \\
\text { eclipse-edition }\end{array}$ & S15 & 0.237410071942446 & 0 & 0.762589928057554 \\
\hline amazon-s3-browser & S15 & 0.201320132013201 & 0 & 0.798679867986799 \\
\hline $\begin{array}{l}\text { mintjams-content- } \\
\text { management }\end{array}$ & S15 & 0.201320132013201 & 0 & 0.798679867986799 \\
\hline
\end{tabular}




\subsubsection{Step 7 - Integrity simulation}

The method simulatelntegrity() of the class observation.java was used to generate simulated observations on solution supplier's integrity. The simulated observations were generated as described in section 3.3.4.4 Integrity.

The simulated trust opinion values resulted after the use of the method simulatelntegrity () are displayed in Table 20.

Table 20: Simulation results with simulated observations about solution suppliers' integrity

\begin{tabular}{|c|c|c|c|c|}
\hline \multirow[b]{2}{*}{ Solution Code } & \multirow[b]{2}{*}{$\begin{array}{l}\text { Scope } \\
\text { Code }\end{array}$} & \multicolumn{3}{|c|}{ Simulated trust opinion values about the solution } \\
\hline & & Belief & Disbelief & Uncertainty \\
\hline $\begin{array}{l}\text { umlet-uml-tool- } \\
\text { fast-uml-diagrams }\end{array}$ & S5 & 0.295486403139893 & 0.00420521446593775 & 0.700308382394169 \\
\hline wireframesketcher & S5 & 0.273453093812375 & 0 & 0.726546906187625 \\
\hline rcp-developer & S5 & 0.261261261261261 & 0 & 0.738738738738739 \\
\hline mylyn-wikitext & S5 & 0.260869565217391 & 0 & 0.739130434782609 \\
\hline jautodoc & S5 & 0.211009174311926 & 0 & 0.788990825688073 \\
\hline Eclox & S5 & 0.198653198653198 & 0 & 0.801346801346801 \\
\hline jdoceditor & S5 & 0.194444444444444 & 0 & 0.8055555555555556 \\
\hline texlipse & S5 & 0.182389937106918 & 0 & 0.817610062893082 \\
\hline subclipse & S15 & 0.298563682271617 & 0 & 0.701436317728383 \\
\hline $\begin{array}{l}\text { subversive-svn- } \\
\text { team-provider }\end{array}$ & S15 & 0.277310924369748 & 0 & 0.722689075630252 \\
\hline $\begin{array}{l}\text { mercurialeclipse- } \\
\text { was-hgeclipse }\end{array}$ & S15 & 0.267326732673267 & 0 & 0.732673267326733 \\
\hline $\begin{array}{l}\text { pulse-download- } \\
\text { manage-and- } \\
\text { maintain-eclipse- } \\
\text { tools }\end{array}$ & S15 & 0.26241134751773 & 0 & 0.73758865248227 \\
\hline $\begin{array}{l}\text { atlassian- } \\
\text { connector-eclipse }\end{array}$ & S15 & 0.254901960784314 & 0 & 0.745098039215686 \\
\hline $\begin{array}{l}\text { collabnet-desktop- } \\
\text { eclipse-edition }\end{array}$ & S15 & 0.221288515406162 & 0 & 0.778711484593837 \\
\hline amazon-s3-browser & S15 & 0.168724279835391 & 0 & 0.831275720164609 \\
\hline $\begin{array}{l}\text { mintjams-content- } \\
\text { management }\end{array}$ & S15 & 0.201320132013201 & 0 & 0.798679867986799 \\
\hline
\end{tabular}




\subsubsection{Step 8 - Combination of all simulations}

Table 21 presents the combination of all simulated observations related to solutions' supplier ability, benevolence, and integrity.

Simulated customer's trust opinion values are updated with the combined results of the methods simulatelntegrity(), simulateBenevolence(), and simulateAbility() of the class observation.java.

Table 21: Simulation results combining simulated observations on ability, benevolence, and integrity

\begin{tabular}{|c|c|c|c|c|}
\hline \multirow[b]{2}{*}{ Solution Code } & \multirow[b]{2}{*}{$\begin{array}{l}\text { Scope } \\
\text { Code }\end{array}$} & \multicolumn{3}{|c|}{ Final simulated trust opinion values about the solution } \\
\hline & & Belief & Disbelief & Uncertainty \\
\hline $\begin{array}{l}\text { umlet-uml-tool- } \\
\text { fast-uml-diagrams }\end{array}$ & S5 & 0.301884437788593 & 0.00524148259078996 & 0.692874079620616 \\
\hline wireframesketcher & S5 & 0.264559794771028 & 0.0229245128541019 & 0.71251569237487 \\
\hline rcp-developer & S5 & 0.279279279279279 & 0 & 0.720720720720721 \\
\hline mylyn-wikitext & S5 & 0.279816513761468 & 0 & 0.720183486238532 \\
\hline jautodoc & S5 & 0.19880418535127 & 0.0448430493273543 & 0.756352765321375 \\
\hline Eclox & S5 & 0.179091688089117 & 0.051413881748072 & 0.769494430162811 \\
\hline jdoceditor & S5 & 0.230505569837189 & 0 & 0.769494430162811 \\
\hline texlipse & S5 & 0.216715257531584 & 0 & 0.783284742468416 \\
\hline subclipse & $\mathrm{S} 15$ & 0.305397585553227 & 0 & 0.694602414446772 \\
\hline $\begin{array}{l}\text { subversive-svn- } \\
\text { team-provider }\end{array}$ & S15 & 0.287303413885692 & 0 & 0.712696586114308 \\
\hline $\begin{array}{l}\text { mercurialeclipse- } \\
\text { was-hgeclipse }\end{array}$ & S15 & 0.284965739621121 & 0 & 0.71503426037888 \\
\hline $\begin{array}{l}\text { pulse-download- } \\
\text { manage-and- } \\
\text { maintain-eclipse- } \\
\text { tools }\end{array}$ & S15 & 0.247126436781609 & 0.0287356321839081 & 0.724137931034483 \\
\hline $\begin{array}{l}\text { atlassian- } \\
\text { connector-eclipse }\end{array}$ & S15 & 0.245227606461087 & 0.0293685756240823 & 0.725403817914831 \\
\hline $\begin{array}{l}\text { collabnet-desktop- } \\
\text { eclipse-edition }\end{array}$ & S15 & 0.249299719887955 & 0 & 0.750700280112045 \\
\hline amazon-s3-browser & S15 & 0.211382113821138 & 0 & 0.788617886178862 \\
\hline $\begin{array}{l}\text { mintjams-content- } \\
\text { management }\end{array}$ & S15 & 0.227792436235708 & 0 & 0.772207563764292 \\
\hline
\end{tabular}




\subsection{Step 9 - Comparing results of simulations and benchmark}

This section presents the absolute and relative impact of the simulations implemented in section 4.4, and provides an indication on whether belief and uncertainty increased or decreased as a result of the different simulations.

Table 22 show the impact of the simulations on customer's belief about the solution in absolute numbers.

Table 22: Belief values

\begin{tabular}{|c|c|c|c|c|c|c|}
\hline Solution Code & $\begin{array}{l}\text { Scope } \\
\text { Code }\end{array}$ & $\begin{array}{c}\text { Benchmark } \\
\text { belief } \\
\text { value } \\
\end{array}$ & $\begin{array}{c}\text { Belief after } \\
\text { ability } \\
\text { simulation }\end{array}$ & $\begin{array}{c}\text { Belief after } \\
\text { benevolence } \\
\text { simulation }\end{array}$ & $\begin{array}{c}\text { Belief after } \\
\text { integrity } \\
\text { simulation } \\
\end{array}$ & $\begin{array}{c}\text { Belief with all } \\
\text { simulations } \\
\text { combined } \\
\end{array}$ \\
\hline $\begin{array}{l}\text { umlet-uml-tool- } \\
\text { fast-uml- } \\
\text { diagrams }\end{array}$ & S5 & 0.29347505 & 0.2992009 & 0.295486403 & 0.2954864 & 0.30188444 \\
\hline $\begin{array}{l}\text { Wireframesketc } \\
\text { her }\end{array}$ & S5 & 0.27345309 & 0.2840982 & 0.250915751 & 0.27345309 & 0.26455979 \\
\hline rcp-developer & S5 & 0.26126126 & 0.2745098 & 0.268292683 & 0.26126126 & 0.27927928 \\
\hline mylyn-wikitext & S5 & 0.26086957 & 0.2751455 & 0.267973856 & 0.26086957 & 0.27981651 \\
\hline Jautodoc & S5 & 0.21100917 & 0.2297064 & 0.178294574 & 0.21100917 & 0.19880419 \\
\hline Eclox & S5 & 0.1986532 & 0.2117528 & 0.165266106 & 0.1986532 & 0.17909169 \\
\hline jdoceditor & S5 & 0.19444444 & 0.2117528 & 0.218390805 & 0.19444444 & 0.23050557 \\
\hline Texlipse & S5 & 0.18238994 & 0.1919906 & 0.21025641 & 0.18238994 & 0.21671526 \\
\hline subclipse & $\mathrm{S} 15$ & 0.29665051 & 0.3028422 & 0.298563682 & 0.29856368 & 0.30539759 \\
\hline $\begin{array}{l}\text { subversive-svn- } \\
\text { team-provider }\end{array}$ & $\mathrm{S} 15$ & 0.27731092 & 0.2838896 & 0.281653747 & 0.27731092 & 0.28730341 \\
\hline $\begin{array}{l}\text { mercurialeclipse } \\
\text {-was-hgeclipse }\end{array}$ & S15 & 0.26732673 & 0.2811821 & 0.273273273 & 0.26732673 & 0.28496574 \\
\hline
\end{tabular}




\begin{tabular}{|l|l|l|l|l|l|l|} 
& & & & & & \\
$\begin{array}{l}\text { pulse-download- } \\
\text { manage-and- } \\
\text { maintain- } \\
\text { eclipse-tools }\end{array}$ & $\mathrm{S} 15$ & 0.26241135 & 0.2704403 & 0.237179487 & 0.26241135 & 0.24712644 \\
\hline $\begin{array}{l}\text { atlassian- } \\
\text { connector- } \\
\text { eclipse }\end{array}$ & $\mathrm{S} 15$ & 0.24444444 & 0.2620321 & 0.215686275 & 0.25490196 & 0.24522761 \\
\hline $\begin{array}{l}\text { collabnet- } \\
\text { desktop-eclipse- } \\
\text { edition }\end{array}$ & $\mathrm{S} 15$ & 0.22128852 & 0.2371795 & 0.237410072 & 0.22128852 & 0.24929972 \\
\hline $\begin{array}{l}\text { amazon-s3- } \\
\text { browser }\end{array}$ & $\mathrm{S} 15$ & 0.16872428 & 0.1840796 & 0.201320132 & 0.16872428 & 0.21138211 \\
\hline $\begin{array}{l}\text { mintjams- } \\
\text { content- } \\
\text { management }\end{array}$ & $\mathrm{S} 15$ & 0.16872428 & 0.1788932 & 0.201320132 & 0.20132013 & 0.22779244 \\
\hline
\end{tabular}

Table 23 shows the impact of the simulation on customer's belief about the solution in relative values. It uses the symbols $\uparrow$ and $\downarrow$ to indicate whether belief increased or decreased.

Table 23: Relative impact on belief after simulation

\begin{tabular}{|c|c|c|c|c|c|c|}
\hline Solution Code & $\begin{array}{c}\text { Scope } \\
\text { Code }\end{array}$ & $\begin{array}{c}\text { Benchmark } \\
\text { belief } \\
\text { value } \\
\end{array}$ & $\begin{array}{c}\% \text { Belief } \\
\text { change after } \\
\text { ability } \\
\text { simulation } \\
\end{array}$ & $\begin{array}{c}\% \text { Belief } \\
\text { change after } \\
\text { benevolence } \\
\text { simulation } \\
\end{array}$ & $\begin{array}{c}\% \text { Belief } \\
\text { change after } \\
\text { integrity } \\
\text { simulation }\end{array}$ & $\begin{array}{c}\text { \% Belief } \\
\text { change with } \\
\text { all } \\
\text { simulations } \\
\text { combined } \\
\end{array}$ \\
\hline $\begin{array}{l}\text { umlet-uml-tool- } \\
\text { fast-uml- } \\
\text { diagrams }\end{array}$ & S5 & 0.2934751 & $1.95 \% \uparrow$ & $0.69 \% \uparrow$ & $0.69 \% \uparrow$ & $2.87 \% \uparrow$ \\
\hline $\begin{array}{l}\text { Wireframesketc } \\
\text { her }\end{array}$ & S5 & 0.2734531 & $3.89 \% \uparrow$ & $-8.24 \% \downarrow$ & $0.00 \%$ & $-3.25 \% \downarrow$ \\
\hline rcp-developer & S5 & 0.2612613 & $5.07 \% \uparrow$ & $2.69 \% \uparrow$ & $0.00 \%$ & $6.90 \% \uparrow$ \\
\hline mylyn-wikitext & S5 & 0.2608696 & $5.47 \% \uparrow$ & $2.72 \% \uparrow$ & $0.00 \%$ & $7.26 \% \uparrow$ \\
\hline
\end{tabular}




\begin{tabular}{|c|c|c|c|c|c|c|}
\hline Jautodoc & S5 & 0.2110092 & $8.86 \% \uparrow$ & $-15.50 \% \downarrow$ & $0.00 \%$ & $-5.78 \% \downarrow$ \\
\hline Eclox & S5 & 0.1986532 & $6.59 \% \uparrow$ & $-16.81 \% \downarrow$ & $0.00 \%$ & $-9.85 \% \downarrow$ \\
\hline jdoceditor & S5 & 0.1944444 & $8.90 \% \uparrow$ & $12.32 \% \uparrow$ & $0.00 \%$ & $18.55 \% \uparrow$ \\
\hline Texlipse & S5 & 0.1823899 & $5.26 \% \uparrow$ & $15.28 \% \uparrow$ & $0.00 \%$ & $18.82 \% \uparrow$ \\
\hline subclipse & $\mathrm{S} 15$ & 0.2966505 & $2.09 \% \uparrow$ & $0.64 \% \uparrow$ & $0.64 \% \uparrow$ & $2.95 \% \uparrow$ \\
\hline $\begin{array}{l}\text { subversive-svn- } \\
\text { team-provider }\end{array}$ & S15 & 0.2773109 & $2.37 \% \uparrow$ & $1.57 \% \uparrow$ & $0.00 \%$ & $3.60 \% \uparrow$ \\
\hline $\begin{array}{l}\text { mercurialeclipse } \\
\text {-was-hgeclipse }\end{array}$ & S15 & 0.2673267 & $5.18 \% \uparrow$ & $2.22 \% \uparrow$ & $0.00 \%$ & $6.60 \% \uparrow$ \\
\hline $\begin{array}{l}\text { pulse-download- } \\
\text { manage-and- } \\
\text { maintain- } \\
\text { eclipse-tools }\end{array}$ & $\mathrm{S} 15$ & 0.2624113 & $3.06 \% \uparrow$ & $-9.62 \% \downarrow$ & $0.00 \%$ & $-5.82 \% \downarrow$ \\
\hline $\begin{array}{l}\text { atlassian- } \\
\text { connector- } \\
\text { eclipse }\end{array}$ & $\mathrm{S} 15$ & 0.2444444 & $7.19 \% \uparrow$ & $-11.76 \% \downarrow$ & $4.28 \% \uparrow$ & $0.32 \% \uparrow$ \\
\hline $\begin{array}{l}\text { collabnet- } \\
\text { desktop-eclipse- } \\
\text { edition }\end{array}$ & $\mathrm{S} 15$ & 0.2212885 & $7.18 \% \uparrow$ & $7.29 \% \uparrow$ & $0.00 \%$ & $12.66 \% \uparrow$ \\
\hline $\begin{array}{l}\text { amazon-s3- } \\
\text { browser }\end{array}$ & $\mathrm{S} 15$ & 0.1687243 & $9.10 \% \uparrow$ & $19.32 \% \uparrow$ & $0.00 \%$ & $25.28 \% \uparrow$ \\
\hline $\begin{array}{l}\text { mintjams- } \\
\text { content- } \\
\text { management }\end{array}$ & $\mathrm{S} 15$ & 0.1687243 & $6.03 \% \uparrow$ & $19.32 \% \uparrow$ & $19.32 \% \uparrow$ & $35.01 \% \uparrow$ \\
\hline
\end{tabular}

Tables 24 show the impact of the simulations on uncertainty values. 
Table 24: Uncertainty values

\begin{tabular}{|c|c|c|c|c|c|c|}
\hline Solution Code & $\begin{array}{l}\text { Scope } \\
\text { Code }\end{array}$ & $\begin{array}{c}\text { Benchmark } \\
\text { uncertainty } \\
\text { values }\end{array}$ & $\begin{array}{l}\text { Uncertainty } \\
\text { after ability } \\
\text { simulation }\end{array}$ & 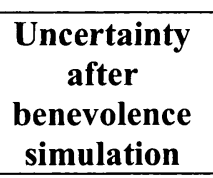 & $\begin{array}{l}\text { Uncertainty } \\
\text { after integrity } \\
\text { simulation }\end{array}$ & $\begin{array}{l}\text { Uncertainty } \\
\text { with all } \\
\text { simulations } \\
\text { combined } \\
\end{array}$ \\
\hline $\begin{array}{l}\text { umlet-uml-tool- } \\
\text { fast-uml- } \\
\text { diagrams }\end{array}$ & S5 & 0.7020963 & 0.6951104 & 0.7003084 & 0.7003084 & 0.6928741 \\
\hline $\begin{array}{l}\text { Wireframesketc } \\
\text { her }\end{array}$ & S5 & 0.7265469 & 0.7159018 & 0.7216117 & 0.7265469 & 0.7125157 \\
\hline rcp-developer & S5 & 0.7387387 & 0.7254902 & 0.7317073 & 0.7387387 & 0.7207207 \\
\hline mylyn-wikitext & S5 & 0.7391304 & 0.7248545 & 0.7320261 & 0.7391304 & 0.7201835 \\
\hline Jautodoc & S5 & 0.7889908 & 0.7702936 & 0.7700258 & 0.7889908 & 0.7563528 \\
\hline Eclox & S5 & 0.8013468 & 0.7882472 & 0.7787115 & 0.8013468 & 0.7694944 \\
\hline jdoceditor & S5 & 0.8055556 & 0.7882472 & 0.7816092 & 0.8055556 & 0.7694944 \\
\hline Texlipse & S5 & 0.8176101 & 0.8080094 & 0.7897436 & 0.8176101 & 0.7832847 \\
\hline Subclipse & $\mathrm{S} 15$ & 0.7033495 & 0.6971578 & 0.7014363 & 0.7014363 & 0.6946024 \\
\hline $\begin{array}{l}\text { subversive-svn- } \\
\text { team-provider }\end{array}$ & S15 & 0.7226891 & 0.7161104 & 0.7183463 & 0.7226891 & 0.7126966 \\
\hline $\begin{array}{l}\text { mercurialeclipse } \\
\text {-was-hgeclipse }\end{array}$ & $\mathrm{S} 15$ & 0.7326733 & 0.7188179 & 0.7267267 & 0.7326733 & 0.7150343 \\
\hline $\begin{array}{l}\text { pulse-download- } \\
\text { manage-and- } \\
\text { maintain- } \\
\text { eclipse-tools }\end{array}$ & $\mathrm{S} 15$ & 0.7375887 & 0.7295597 & 0.7307692 & 0.7375887 & 0.7241379 \\
\hline $\begin{array}{l}\text { atlassian- } \\
\text { connector- } \\
\text { eclipse }\end{array}$ & $\mathrm{S} 15$ & 0.7555556 & 0.7379679 & 0.745098 & 0.745098 & 0.7254038 \\
\hline $\begin{array}{l}\text { collabnet- } \\
\text { desktop-eclipse- } \\
\text { edition }\end{array}$ & S15 & 0.7787115 & 0.7628205 & 0.7625899 & 0.7787115 & 0.7507003 \\
\hline $\begin{array}{l}\text { amazon-s3- } \\
\text { browser }\end{array}$ & $\mathrm{S} 15$ & 0.8312757 & 0.8159204 & 0.7986799 & 0.8312757 & 0.7886179 \\
\hline $\begin{array}{l}\text { mintjams- } \\
\text { content- } \\
\text { management }\end{array}$ & $\mathrm{S} 15$ & 0.8312757 & 0.8211068 & 0.7986799 & 0.7986799 & 0.7722076 \\
\hline
\end{tabular}


Table 25 shows the impact of the simulation on customer's uncertainty about the solution in relative values. It uses the symbols $\uparrow$ and $\downarrow$ to indicate whether uncertainty increased or decreased. In the column "Belief after integrity simulation" NA means that no simulated observations on integrity were applied to the solution.

Table 25: Percentage change on uncertainty values after simulation

\begin{tabular}{|c|c|c|c|c|c|c|}
\hline Solution Code & $\begin{array}{l}\text { Scope } \\
\text { Code }\end{array}$ & $\begin{array}{c}\text { Benchmark } \\
\text { uncertainty } \\
\text { value }\end{array}$ & $\begin{array}{l}\text { \% Uncertainty } \\
\text { change after } \\
\text { ability } \\
\text { simulation }\end{array}$ & $\begin{array}{c}\% \\
\text { Uncertainty } \\
\text { change after } \\
\text { benevolence } \\
\text { simulation }\end{array}$ & $\begin{array}{c}\% \\
\text { Uncertainty } \\
\text { change after } \\
\text { integrity } \\
\text { simulation }\end{array}$ & $\begin{array}{c}\% \\
\text { Uncertainty } \\
\text { change with } \\
\text { all } \\
\text { simulations } \\
\text { combined }\end{array}$ \\
\hline $\begin{array}{l}\text { umlet-uml-tool- } \\
\text { fast-uml- } \\
\text { diagrams }\end{array}$ & S5 & 0.7020963 & $-1.00 \% \downarrow$ & $-0.25 \% \downarrow$ & $-0.25 \% \downarrow$ & $-1.31 \%$ \\
\hline $\begin{array}{l}\text { Wireframesketc } \\
\text { her }\end{array}$ & S5 & 0.7265469 & $-1.47 \% \downarrow$ & $-0.68 \% \downarrow$ & NA & $-1.93 \%$ \\
\hline rcp-developer & S5 & 0.7387387 & $-1.79 \% \downarrow$ & $-0.95 \% \downarrow$ & NA & $-2.44 \%$ \\
\hline mylyn-wikitext & S5 & 0.7391304 & $-1.93 \% \downarrow$ & $-0.96 \% \downarrow$ & NA & $-2.56 \%$ \\
\hline Jautodoc & S5 & 0.7889908 & $-2.37 \% \downarrow$ & $-2.40 \% \downarrow$ & NA & $-4.14 \%$ \\
\hline Eclox & S5 & 0.8013468 & $-1.63 \% \downarrow$ & $-2.82 \% \downarrow$ & NA & $-3.97 \%$ \\
\hline Jdoceditor & S5 & 0.8055556 & $-2.15 \% \downarrow$ & $-2.97 \% \downarrow$ & NA & $-4.48 \%$ \\
\hline Texlipse & S5 & 0.8176101 & $-1.17 \% \downarrow$ & $-3.41 \% \downarrow$ & NA & $-4.20 \%$ \\
\hline Subclipse & S15 & 0.7033495 & $-0.88 \% \downarrow$ & $-0.27 \% \downarrow$ & $-0.27 \% \downarrow$ & $-1.24 \%$ \\
\hline $\begin{array}{l}\text { subversive-svn- } \\
\text { team-provider }\end{array}$ & S15 & 0.7226891 & $-0.91 \% \downarrow$ & $-0.60 \%$ & $\mathrm{NA}$ & $-1.38 \%$ \\
\hline $\begin{array}{l}\text { mercurialeclipse } \\
\text {-was-hgeclipse }\end{array}$ & $\mathrm{S} 15$ & 0.7326733 & $-1.89 \% \downarrow$ & $-0.81 \% \downarrow$ & NA & $-2.41 \%$ \\
\hline $\begin{array}{l}\text { pulse-download- } \\
\text { manage-and- } \\
\text { maintain- } \\
\text { eclipse-tools }\end{array}$ & S15 & 0.7375887 & $-1.09 \% \downarrow$ & $-0.92 \% \downarrow$ & NA & $-1.82 \%$ \\
\hline
\end{tabular}




\begin{tabular}{|l|l|l|l|l|l|l|}
$\begin{array}{l}\text { atlassian- } \\
\text { connector- } \\
\text { eclipse }\end{array}$ & $\mathrm{S} 15$ & 0.7555556 & $-2.33 \% \downarrow$ & $-1.38 \% \downarrow$ & $-1.38 \% \downarrow$ & $-3.99 \% \downarrow$ \\
\hline $\begin{array}{l}\text { collabnet- } \\
\text { desktop-eclipse- } \\
\text { edition }\end{array}$ & $\mathrm{S} 15$ & 0.7787115 & $-2.04 \% \downarrow$ & $-2.07 \% \downarrow$ & $\mathrm{NA}$ & $-3.60 \% \downarrow$ \\
\hline $\begin{array}{l}\text { amazon-s3- } \\
\text { browser }\end{array}$ & $\mathrm{S} 15$ & 0.8312757 & $-1.85 \% \downarrow$ & $-3.92 \% \downarrow$ & $\mathrm{NA}$ & $-5.13 \% \downarrow$ \\
\hline $\begin{array}{l}\text { mintjams- } \\
\text { content- } \\
\text { management }\end{array}$ & $\mathrm{S} 15$ & 0.8312757 & $-1.22 \% \downarrow$ & $-3.92 \% \downarrow$ & $-3.92 \% \downarrow$ & $-7.11 \% \downarrow$ \\
\hline
\end{tabular}




\section{RESULTS AND DISCUSSION}

This chapter is organized into two sections. The first section provides the simulation results. The second section discusses the results.

\subsection{Results}

\section{Customer uncertainty decreases with additional observations.}

Results in Tables 24 and 25 show that customer uncertainty decreases in all simulation scenarios. In Table 24, uncertainty values in the columns "Uncertainty after ability simulation", "Uncertainty after benevolence simulation", "Uncertainty after integrity simulation", and "Uncertainty with all simulations combined" are lower than the corresponding uncertainty values in the column "Benchmark uncertainty values". Table 25 provides the percentage uncertainty is lower on each simulation.

Belief does not necessarily increase or decrease with additional observations.

Results in Table 23 show that belief doesn't necessarily just increase or decrease with additional observations. Customers can use additional observations to decrease uncertainty by increasing disbelief if the observations are not positive. The column "\% Belief change after benevolence simulation" show that a solution supplier perceived as non-benevolent can have its belief values decreased. 
Results in Tables 18 and 23 show that in the ability simulation all solutions had their belief value increased. Figure 14 show that solutions with lower initial belief had the most relative benefit from the simulation results.

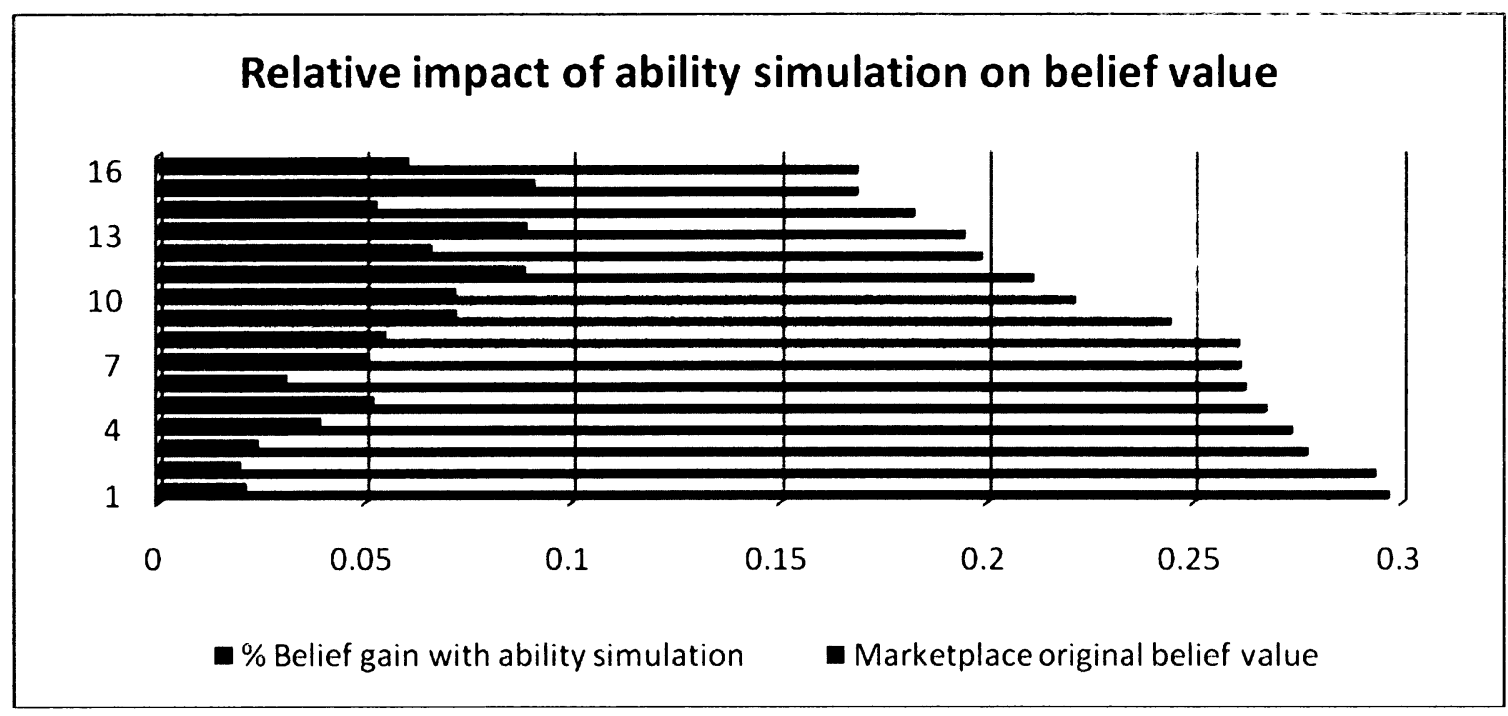

Figure 14: Relative impact of ability simulation on belief value

Results in Tables 19 and 23 show that in the benevolence simulation, by having the keystone allowing solution suppliers to post whitepapers it was possible to identify that belief decreased for solution suppliers that didn't collaborate sharing their knowledge and increased for suppliers that shared their knowledge.

Results in Table 23 also show that, from the solution suppliers that had their belief values decreased, the solution suppliers with lower initial belief were the most 
negatively impacted by the results of the simulation. By the other hand, solution suppliers with higher initial belief didn't benefit too much from the simulation.

\subsection{Results discussion}

The simulation results allow us to assess how the numbers of observations about solution supplier's ability, benevolence, and integrity affect customer's uncertainty and belief on a solution.

Results suggest that customer uncertainty can be decreased with additional observations on solution suppliers. All simulation scenarios show that uncertainty decreases when additional information about a solution supplier's ability, integrity, and benevolence are made available. On average, uncertainty values decrease $3.23 \%$ when 309 observations are added (average of 19.3 additional observations per solution).

Keystone operators can take advantage of this finding by providing as much information as possible about their members and about the solutions announced in their marketplaces.

Providing additional observations on solutions suppliers does not necessarily increases the belief in a solution. Belief increases or decreases based on the judgment made about such observations to identify them as positive or negative.

Providing ways to allow solution supplier's to share knowledge (e.g., whitepapers) with marketplace members makes it possible for potential customers to identify which 
suppliers share and which suppliers do not share information with the community. While the first group that shares their knowledge would have their belief value increased, the second group identified as not willing to share would have their belief decreased.

Keystone operators seeking the best interest of their customers can provide suppliers with as many mechanisms as possible to allow them to show their benevolence. It is on the suppliers' hands to use such mechanisms to gain customers' belief in their solutions. Information that shows a solution suppliers' benevolence should always be made public on a marketplace website (e.g., suppliers participating in organizations that advocate customers' agenda, suppliers' statements that their success depends on their customers' success).

Observations that show a solution suppliers' ability help to increase customer's belief. Solution suppliers should provide as much evidence as possible about their ability to deliver a solution. An average increase of $5.51 \%$ on belief was observed in the ability simulation.

Keystone operators can enable solution suppliers to show their integrity to potential customers by providing them with ways that attest their correctness to deliver what they said they would deliver. 


\section{CONCLUSIONS, LIMITATIONS, AND FUTURE RESEARCH}

This chapter is organized into three sections. The first section provides the conclusions of this research. The second section provides the limitations of this research. The third section provides opportunities for future research.

\subsection{Conclusions}

This research integrates two literature streams: (i) trust dimensions and (ii) trust network analysis with subjective logic.

Based on the results of this research I conclude that:

The results of this research led us to the following conclusions:

- Trust opinion values decrease customers' uncertainty about a supplier's solution.

- Adding observations on a solution supplier's ability, integrity, and benevolence does not necessarily increase belief in the solution. The belief value of a trust opinion is dependent on the quality of each observation. Marketplaces and solution suppliers seeking to increase trust in the published solutions should seek quality instead of quantity of observations about solutions made available to potential customers. 
- We can expand Jøsang's trust network analysis model by calculating trust opinion values based on observations on suppliers' ability, integrity, and benevolence.

\subsection{Limitations}

This research has at least two limitations:

1. Marketplace member's reviews were analyzed based on the researcher's judgement. It was possible because from the 321 observations only 18 were member's reviews. An automated method to interpret the content of marketplace member's reviews should be considered when looking at a larger amount of observations.

2. Benevolence simulation was based on solution supplier's sharing their knowledge with the marketplace community by preparing and posting whitepapers. Other better ways to assess a solution suppliers' benevolence should be considered on different simulation scenarios.

\subsection{Future research}

This research identifies three opportunities for future research:

1. As adding observations on a solution supplier's ability, integrity, and benevolence does not necessarily increase belief, other methods to increase belief on a solution announced in a marketplace should be considered in a future research. 
2. The conclusions were taken based on the combination trust opinions of three trust arcs in a trust network $(\omega 1, \omega 2$, and $\omega 3)$ using TNA-SL. A new study could also investigate the implications and impact of each trust dimensions for each trust opinion of each trust arc of a marketplace separately.

3. Examine evidence of benevolence with different ways to assess a solution suppliers' benevolence. 


\section{REFERENCES}

- Bhuyan, T., \& Jøsang, A. 2010. Analysing trust transitivity and the effects of unknown dependence. Journal of Engineering Business Management, Vol. 2, No. 1

- Chandrasekharan, S., \& Esfandiari, B. 2000. Building Trustable Agents, Carleton University Research Report SCE-00-04, Ottawa, Canada

- Charmaz, K. 2006. Constructing grounded theory: A practical guide through qualitative analysis. SAGE Publication, London, Thousand Oaks, New Delhi.

- Das, T. K., \& Bing-Sheng Teng. 1998. Between trust and control: developing confidence in partner cooperation in alliances. Academy of Management Review, Vol. 23. No. 3

- Dirks, K. T., \& Ferrin, D. L. 2001. The role of trust in organizational settings. Organization Science, Jul/Aug2001, Vol. 12 Issue 4, p450-467

- Donato, D., \& Stefano, L., \& Paniccia, M. 2008. Combining transitive trust and negative opinions for better reputation management in social networks. Workshop on Social Network Mining and Analysis (SNA-KDD), Las Vegas, NV

- European Comission, 2005. Giving more for research in Europe: The role of foundations and the non-profit sector in boosting R\&D investment.

- Gueguen, G., \& Pellegrin-Boucher, \& E., Torres, O. 2006. Between cooperation and competition: the benefits of collective strategies within business ecosystems. The example of software industry. $2^{\text {nd }}$ Workshop on coopetition strategy. Milan, Italy.

- Huang, J., \& Fox, M. S. 2006. An ontology of trust - Formal semantics and transitivity. ICEC, August, 2006, Fredericton, Canada

- Huang, J., \& Nicol, D. 2009. A calculus of trust and Its application to PKI and identity management. IDTrust '09, April14-16, 2009, Gaithersburg, MD, USA 
- lansiti, M., \& Levien, R. 2004. The keystone advantage: what the new dynamics of business ecosystems mean for strategy, innovation, and sustainability. Harvard Business School.

- lansiti, M., \& Richards, G.L. 2006. The information technology ecosystem: structure, health and performance. The Antitrust Bulletin, Vol. 51, No.1.

- Jøsang, A. 2009. Draft subjective logic book. Available at: http://persons.unik.no/josang/sl/

- Jøsang, A., \& Bhuiyan, T. 2008. Optimal trust network analysis with subjective logic. $2^{\text {nd }}$ International Conference on Emergin Security Information, Systems and Technologies, Cap Esterel, France, August 2008

- Jøsang, A., \& Gray, E., \& Kinateder, M. 2006. Simplification and analysis of transitive trust networks. Web Intelligence and Agent System, Vol. 4 No. 2, 139161

- Klein, Daniel B. The demand for and supply of assurance. Economic Affairs; Vol. 21 Issue 1, p. March 2001

- Letts, C. W.; Ryan, W.; Grossman, A. 1997.Virtuous capital: What foundations can learn from venture capitalists. Harvard Business Review; Mar/Apr97, Vol. 75 Issue 2, p36-44

- Levin, D. Z., \& Whitener, E. M., \& Cross, R. 2006. Perceived trustworthiness of knowledge sources: The moderating impact of relationship length. Journal of Applied Psychology; Vol. 91, No.5, p.1163-1171

- Lifen, L. 2008. Trust derivation and transitivity in a recommendation trust model. 2008 International Conference on Computer Science and Software Engineering.

- Marsh, S. P. 1994. Formalising trust as a computational concept. Ph. D. Thesis, University of Stirling, April 1994

- Mayer, R., \& Davis, J., \& Schoorman, F. D. 1995. An integrative model of organizational trust. Academy of Management Review, Jul 95, Vol. 20 Issue 3, 709-734 
- Mcknight, D. H., \& Cummings, L. L., \& Chervany. 1998. Initial trust formation in new organizational relationships. Academy of Management Review, Vol. 23, No.3

- Moore, J.F. 1996. The death of competition: Leadership and strategy in the age of business ecosystems. HarperCollins Publishers. New York, NY.

- Moore, J.F. 2006. Business ecosystems and the view from the firm. The Antitrust Bulletin, Vol. 51, No.1.

- Mouzas, S., \& Henneberg, S., \& Naudé, P. 2007. Trust and reliance in business relationships. European Journal of Marketing, Vol. 41, 1016-1032

- Nooteboom, B. 2004. Inter-firm collaboration, networks and strategy [electronic resource]: an integrated approach. Routledge, New York, NY.

- Nalebuff, B. J., Brandenburger, A. M. 2007. Co-opetition. Bloomsbury Business Library - Management Library

- O'Mahony, S. 2003. Non-profit foundations and their role in community-firm software collaboration. O'Reilly \& Associates Publications.

- Olekalns, M., \& Smith, P. L. 2007. The relational foundations of strategic choice in negotiation. International Association of Conflict Management Conference. Available at: http://works.bepress.com/mara_olekalns/17

- Pardue, J. H., \& Jeffrey, P. L., \& Christopher, E. S. 2008. Trustworthiness computer-mediated transactions: A Content Analysis of Truster Feedback. Journal of Technology Research, Vol. 1, URL: http://aabri.com/manuscripts/08007.pdf

- Pavlou, P. A., \& Dimoka, A. 2006. The nature and role of feedback text comments in online marketplaces: Implications for trust building, Price Premiums, and Seller Differentiation. Information Systems Research. August 2006 
- Peltoniemi, M., \& Vuori, E., \& Laihonen, H. 2006. Business ecosystem as a tool for the conceptualization of the external diversity of an organization. Tampere University of Technology, Institute of Business Information Management.

- Poel, P. E. F. 2005. Informal institutions, transaction costs and trust. Master thesis presented for the study International Development Studies at the University of Amsterdam.

- Powell, W., \& Steinberg, R. 2006. The nonprofit sector: a research handbook. $2^{\text {nd }}$ ed. Yale University, New Haven, CT.

- Ratnasingam, P. 2005. Trust in Inter-organizational exchanges: a case study in business to business electronic commerce. Decision Support Systems, Vol. 39, 525-544

- Ring, P. S., \& Van de Ven, A. H. 1992. Structuring cooperative relationships between organizations. Strategic Management Journal, Vol. 13, 483-498

- Ring, P. S., \& Van de Ven, A. H. 1994. Developmental processes of cooperative interorganizational relationships. Academy of Management Review, Vol. 19, No.1

- Shi, J, \& Bochmann, G. v.; \& Adams, C. 2004. A trust model with statistical foundation. In FAST'04, $2^{\text {nd }}$ International Workshop on Formal Aspects in Security and Trust (pp.145-158).Toulouse, France.

- Shoorman, F. D., \& Mayer, R. C., \& Davis, J. H. 2007. An integrative model of organizational trust: past, present, and future. Academy of Management Review, Vol. 32, No.2.

- Svensson, G., \& Wood, G. 2004. Corporate ethics and trust in intra-corporate relationships: an in-depth and longitudinal case description. Employee Relations, Vol. 26, No. 3

- Tullberg, J. 2008. Trust - The importance of trustfulness versus trustworthiness. The Journal of Socio-Economics, vol. 37, 2059-2071 
- West, J., \& O'Mahoney, S. 2008. The role of participation architecture in growing sponsored open source communities. Industry and Innovation.

- Yandle, Bruce. 2010. Lost trust: the real cause of the financial meltdown. Independent Review, Winter 2010

- Zhensheng, Xie. 2008. Open source software foundation: Company involvement, governance and effectiveness. TIM thesis. Carleton University, Ottawa, ON. 


\section{APPENDIX A - Notation for trust arcs and trust paths}

In this research we will use a slightly modified version of the notation proposed by Jøsang et al. (2006). A simple trust relationship is expressed as follow:

$[\mathrm{A}, \mathrm{B}]$

In the example above we have the trust arc $[A, B]$ meaning that $A$ trusts $B$.

Scope is expressed using the symbol $\sigma$. The variants of the scope (referral trust or functional trust) are represented by the letters $\mathrm{r}$ and $\mathrm{f}$. The distinction between direct and indirect trust is represented by the letters $\mathrm{d}$ and $\mathrm{i}$. The possible combinations are exemplified below:

[A, B, dr. $\sigma] \quad \mathrm{A}$ has direct referral trust in B about $\sigma$ $[\mathrm{A}, \mathrm{B}, \mathrm{ir} . \sigma] \quad \mathrm{A}$ has indirect referral trust in $\mathrm{B}$ about $\sigma$ $[\mathrm{A}, \mathrm{B}, \mathrm{df} . \sigma] \quad \mathrm{A}$ has direct functional trust in B about $\sigma$ $[\mathrm{A}, \mathrm{B}$, if. $\sigma] \quad \mathrm{A}$ has indirect functional trust in $\mathrm{B}$ about $\sigma$

A transitive trust path is represented using the symbol ":". A transitive trust path from node $A$ to node $C$ through node $B$ can be expressed as follow:

$$
([\mathrm{A}, \mathrm{C}, \text { if. } \sigma])=([\mathrm{A}, \mathrm{B}, \mathrm{dr} . \sigma]:[\mathrm{B}, \mathrm{C}, \mathrm{df} . \sigma])
$$

Parallel trust paths can be expressed by the symbol " $\diamond$ ". An example for two trust transitive paths between $A$ and $C$, one trough $B$ and another through $D$, can be expressed as follow: 


$$
([\mathrm{A}, \mathrm{C}, \text { if. } \sigma])=(([\mathrm{A}, \mathrm{B}, \mathrm{dr} . \sigma]:[\mathrm{B}, \mathrm{C}, \mathrm{df} . \sigma]) \diamond([\mathrm{A}, \mathrm{D}, \mathrm{dr} . \sigma]:[\mathrm{D}, \mathrm{C}, \mathrm{df} . \sigma]))
$$

Jøsang et al. (2006) also presents a method about how complex transitive trust networks can be simplified. Simplification of trust networks is not in the scope of this present research.

In this research when expressing trust arcs, the symbol $\sigma$ is substituted with a scope code associated with a solution code.

The pattern to represent for trust arcs used in this research is:

[truster, trustee, scope variant.scope code]

Example:

[customer, texlipse, if.SOL.S5]

The scope variants and scope codes used in this research are:

$\begin{array}{ll}\text { dr.KEY } & \text { Direct referral trust in a keystone } \\ \text { dr.REV } & \text { Direct referral trust in a reviewer (marketplace member) } \\ \text { df.SOL } & \text { Direct functional trust in a solution } \\ \text { if.SOL } & \text { Indirect functional trust in a solution }\end{array}$

The scope codes and scope codes used in this research are:

S5 Documentation

S15 Team development 


\section{APPENDIX B - Notation for trust opinions}

Trust opinions are expressed with the following notation:

$\omega[\mathrm{A}, \mathrm{B}, \sigma]=(\mathrm{b}, \mathrm{d}, \mathrm{u}, \mathrm{a})$

Where:

$\omega[\mathrm{A}, \mathrm{B}, \sigma] \quad$ represents then opinion of $\mathrm{A}$ about $\mathrm{B}$ regarding $\sigma$

(b, d, u, a) represents (belief, disbelief, uncertainty, and a-priori trust)

In an opinion the values of belief, disbelief, and uncertainty sum to 1 . Increasing any one of these parameters will decrease one or both other parameters.

$$
\mathrm{b}+\mathrm{d}+\mathrm{u}=1
$$

Trust opinion values belief, disbelief, and uncertainty are calculated based on the number of positive ( $r$ ) and negative (s) observations from the truster about the trustee.

Belief is calculated with the following formula:

$$
\mathrm{b}=\mathrm{r} /(\mathrm{r}+\mathrm{s}+2)
$$

Disbelief is calculated with the following formula:

$$
\mathrm{d}=\mathrm{s} /(\mathrm{r}+\mathrm{s}+2)
$$

Uncertainty is calculated with the following formula:

$$
\mathrm{u}=2 /(\mathrm{r}+\mathrm{s}+2)
$$

The a-priori trust value (a) is defined by the predisposition that the truster has to establish an initial trust in a trustee even in the absence of any evidence. 
In this research when expressing a trust opinion, we follow the pattern:

$(\omega[$ truster, trustee, scope variant.scope code $]=\{b, d, u, a\})$

\section{Example:}

$(\omega[$ EF,user3708,dr.REV.S5] $=\{0.5,0.0,0.5,0.5\})$ 


\section{APPENDIX C - Notation for discounting and consensus}

Discounting is represented by following notation:

$\omega[\mathrm{A}, \mathrm{C}, \sigma]=\omega[\mathrm{A}, \mathrm{B}, \sigma] \otimes \omega[\mathrm{B}, \mathrm{C}, \sigma]$

A discounted opinion is calculated by applying the following formulas:

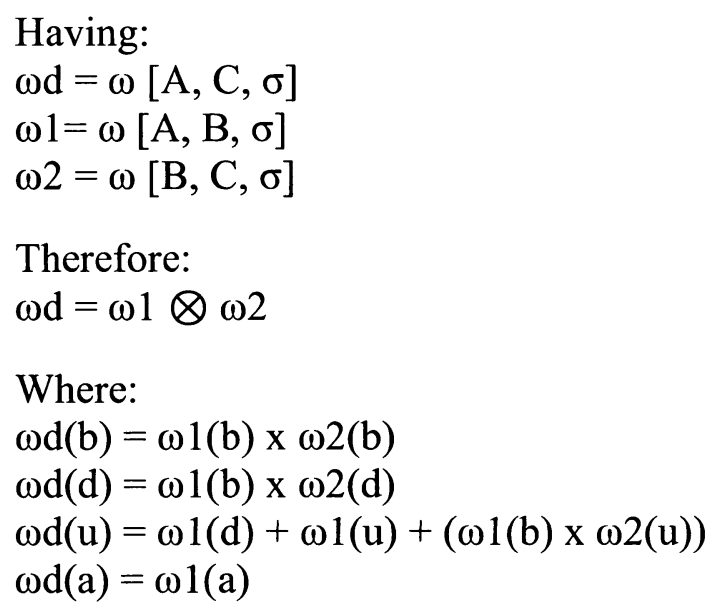

Consensus is represented by the following notation:

$\omega[\mathrm{A} \diamond \mathrm{B}, \mathrm{C}, \sigma]=\omega[\mathrm{A}, \mathrm{C}, \sigma] \oplus \omega[\mathrm{B}, \mathrm{C}, \sigma]$

A consensual opinion is calculated by applying the following formulas:

Having:

$$
\begin{aligned}
& \omega \mathrm{c}=\omega[\mathrm{A} \diamond \mathrm{B}, \mathrm{C}, \sigma] \\
& \omega 1=\omega[\mathrm{A}, \mathrm{C}, \sigma] \\
& \omega 2=\omega[\mathrm{B}, \mathrm{C}, \sigma]
\end{aligned}
$$


Therefore:

$\omega c=\omega 1 \otimes \omega 2$

Where:

$\omega c(b)=(\omega 1(b) \cdot \omega 2(u)+\omega 2(b) \cdot \omega 1(u)) /(\omega 1(u)+\omega 2(u)-\omega 1(u) \times \omega 2(u))$

$\omega c(d)=(\omega 1(d) \cdot \omega 2(u)+\omega 2(d) \cdot \omega 1(u)) /(\omega 1(u)+\omega 2(u)-\omega 1(u) \times \omega 2(u))$

$\omega c(u)=(\omega 1(u) \cdot \omega 2(u)) /(\omega 1(u)+\omega 2(u)-\omega 1(u) \times \omega 2(u))$

$\omega c(a)=\omega 1(a)$ 


\section{APPENDIX D - List of solution categories from Eclipse Marketplace}

Category name (number of solutions)

Application Management (48)

Application Server (19)

BIRT (5)

Build and Deploy (69)

Code Management (56)

Database (39)

Database Persistence (9)

Documentation (29)

Editor (106)

Entertainment (8)

Graphics (18)

IDE (133)

J2EE Development Platform (33)

J2ME (10)

Languages (60)

Logging (5)

Modeling Tools (75)

Mylyn Connectors (15)

Network (9)

Other (36)

Process (21)

Profiling (12)

Reporting (12)

Rich Client Applications (27)

SCM (18)

Search (9)

Source Code Analyzer (55)

Systems Development (18)

Team Development (46)

Testing (66)

Tools (250)

UI (54)

UML (40)

Web (47)

Web Services (20)

XML (22) 


\section{APPENDIX E - List of all solutions from the category "Documentation"}

\begin{tabular}{|l|l|l|}
\hline SolutionCode & SolutionName & ScopeCode \\
\hline $\begin{array}{l}\text { instinctools-ditaworks- } \\
\text { documentation-tool }\end{array}$ & $\begin{array}{l}\text { *instinctools DITAworks } \\
\text { Documentation Tool }\end{array}$ & S5 \\
\hline mylyn-wikitext & Mylyn WikiText & S5 \\
\hline rcp-developer & RCP Developer & S5 \\
\hline agilej-structureviews & AgileJ StructureViews & S5 \\
\hline amazon-s3-browser & Amazon S3 Browser & S5 \\
\hline apt-editor & APT Editor & S5 \\
\hline dtp-cheat-sheet-eclipse-34 & DTP Cheat Sheet for Eclipse 3.4 & S5 \\
\hline eclipse-code-recommenders & Eclipse Code Recommenders & S5 \\
\hline eclipse-help-topics & eclipse help topics & S5 \\
\hline Eclox & Eclox & S5 \\
\hline feature-working-sets & Feature Working Sets & S5 \\
\hline fx2doc & Fx2Doc & S5 \\
\hline Gluebox & Gluebox & S5 \\
\hline i-net-doqua & i-net Doqua & S5 \\
\hline Jautodoc & JAutodoc & S5 \\
\hline jboss-seam-eclipse-help-plugin & JBoss Seam Eclipse Help Plugin & S5 \\
\hline Jdoceditor & JDocEditor & S5 \\
\hline $\begin{array}{l}\text { jindent-source-code-formatter- } \\
\text { javacc }\end{array}$ & $\begin{array}{l}\text { Jindent - Source Code Formatter for } \\
\text { Java/C/C++ }\end{array}$ & S5 \\
\hline mintjams-content-management & MintJams Content Management & S5 \\
\hline nqdoc-document-processor & nqDoc Document Processor & S5 \\
\hline relations-0 & Relations & S5 \\
\hline rss-view & RSS View & S5 \\
\hline se-editor & SE-Editor & S5 \\
\hline source-code-search-engine & Source Code Search Engine & S5 \\
\hline texlipse & TeXlipse & S5 \\
\hline tip-day & Tip Of The Day & S5 \\
\hline umlet-uml-tool-fast-uml-diagrams & UMLet - UML Tool for Fast UML & S5 \\
Diagrams & S5 \\
\hline wireframesketcher & WireframeSketcher & S5 \\
\hline yep-apt-editor & YEP APT Editor & \\
\hline & & \\
\hline
\end{tabular}




\section{APPENDIX F - List of all solutions from the category "Team Development"}

\begin{tabular}{|c|c|c|}
\hline SolutionCode & SolutionName & ScopeCode \\
\hline collabnet-desktop-eclipse-edition & CollabNet Desktop - Eclipse Edition & S15 \\
\hline $\begin{array}{l}\text { pulse-download-manage-and- } \\
\text { maintain-eclipse-tools }\end{array}$ & $\begin{array}{l}\text { Pulse | Download, manage and } \\
\text { maintain Eclipse tools }\end{array}$ & S15 \\
\hline $\begin{array}{l}\text { solution-blueprint-community- } \\
\text { edition }\end{array}$ & $\begin{array}{l}\text { Solution Blueprint - Community } \\
\text { Edition }\end{array}$ & S15 \\
\hline subversive-svn-team-provider & Subversive - SVN Team Provider & S15 \\
\hline accurev-accubridge-eclipse-plug & $\begin{array}{l}\text { AccuRev AccuBridge for Eclipse } \\
\text { Plug-In }\end{array}$ & S15 \\
\hline $\begin{array}{l}\text { annotate-add-ibm-rational- } \\
\text { clearcase-scm-adapter }\end{array}$ & $\begin{array}{l}\text { Annotate Add-On for the IBM } \\
\text { Rational ClearCase SCM Adapter }\end{array}$ & S15 \\
\hline atlassian-connector-eclipse & Atlassian Connector for Eclipse & S15 \\
\hline bazaar-plugin-eclipse & Bazaar plugin for Eclipse & S15 \\
\hline boneclipse-cvsgrapher & boneclipse-cvsgrapher & S15 \\
\hline ceno & Ceno & S15 \\
\hline code-collaborator & Code Collaborator & S15 \\
\hline codebeamer-eclipse-studio & codeBeamer Eclipse Studio & S15 \\
\hline codebeamer-plugin-eclipse & codeBeamer Plugin for Eclipse & S15 \\
\hline commit-20 & Commit 2.0 & S15 \\
\hline cruise-control-eclipse-plugin & Cruise Control Eclipse Plugin & $\mathrm{S} 15$ \\
\hline $\begin{array}{l}\text { eclipse-subversion-plugin- } \\
\text { integrated-total-alm-solution- } \\
\text { easyflow }\end{array}$ & $\begin{array}{l}\text { Eclipse-Subversion Plugin integrated } \\
\text { with a total ALM solution - Easy!Flow }\end{array}$ & S15 \\
\hline ganttchart-clearquest & GanttChart for ClearQuest & S15 \\
\hline magicdraw & MagicDraw & S15 \\
\hline mercurial-eclipse & Mercurial Eclipse & S15 \\
\hline mercurialeclipse-was-hgeclipse & MercurialEclipse (was: HgEclipse) & S15 \\
\hline plastic-scm-eclipse-plug & Plastic SCM Eclipse Plug-In & S15 \\
\hline project-set-plugin & Project Set Plugin & S15 \\
\hline projectcards & ProjectCards & S15 \\
\hline projectkoach-premium & ProjectKoach Premium & S15 \\
\hline projectkoach-team & ProjectKoach Team & S15 \\
\hline remote-project-properties-plug & Remote Project Properties Plug-in & S15 \\
\hline $\begin{array}{l}\text { remote-workspace-preferences- } \\
\text { plug }\end{array}$ & $\begin{array}{l}\text { Remote Workspace Preferences } \\
\text { Plug-in }\end{array}$ & S15 \\
\hline remove-tag-tool & Remove Tag Tool & S15 \\
\hline reviewclipse & ReviewClipse & S15 \\
\hline roundTable-team & RoundTable Team & S15 \\
\hline $\begin{array}{l}\text { saros-distributed-collaborative- } \\
\text { editing-and-pair-programming }\end{array}$ & $\begin{array}{l}\text { Saros - Distributed Collaborative } \\
\text { Editing and Pair Programming }\end{array}$ & $\mathrm{S} 15$ \\
\hline snipper-code-sharing-service & Snipper - Code Sharing Service & S15 \\
\hline
\end{tabular}




\begin{tabular}{|l|l|l|}
\hline sourcegear-fortress-plugin-eclipse & $\begin{array}{l}\text { SourceGear Fortress Plugin for } \\
\text { Eclipse }\end{array}$ & S15 \\
\hline sourcegear-vault-plugin-eclipse & SourceGear Vault Plugin for Eclipse & S15 \\
\hline spectrumscm-plugin-eclipse & SpectrumSCM Plugin for Eclipse & S15 \\
\hline subclipse & Subclipse & S15 \\
\hline svn-reporter-plugin & SVN Reporter Plugin & S15 \\
\hline svnadmin & SvnAdmin & S15 \\
\hline synergy-alm & Synergy ALM & S15 \\
\hline tracklipse-track-issue-tracker & Tracklipse for Track+ Issue Tracker & S15 \\
\hline twikle & Twikle & S15 \\
\hline $\begin{array}{l}\text { xpairtise-pair-programming- } \\
\text { eclipse }\end{array}$ & $\begin{array}{l}\text { XPairtise - Pair Programming for } \\
\text { Eclipse }\end{array}$ & S15 \\
\hline
\end{tabular}




\section{Appendix $G$ - Results of building a transitive trust network \\ from customer to solution textlipse}

TNA-SL

\section{Indirect Trust Arc}

[customer, texlipse, if.SOL.S5]

\section{Transitive Trust Paths}

[customer,EF] : [EF,user3708] : [user3708,texlipse] [customer,EF] : [EF,user1295] : [user1295,texlipse] [customer,EF] : [EF,user1474]: [user1474,texlipse] [customer,EF] : [EF,user1624] : [user1624,texlipse]

\section{Canonical Expression}

$([$ customer, texlipse $])=([$ customer, EF] $):(([\mathrm{EF}$, user3708] $:[$ user3708,texlipse $]) \diamond$ $([\mathrm{EF}$, user1295]: [user1295,texlipse] $) \diamond([\mathrm{EF}$, user1474] : [user1474,texlipse] $) \diamond([\mathrm{EF}$, user1624] : [user1624,texlipse]))

\section{Discounting: (keystone : members) $\otimes$ (members : solution)}

$(\omega[E F$, user3708,dr.REV.S5] $=\{0.5,0.0,0.5,0.5\}) \otimes$

$(\omega[$ user3708,texlipse,df.SOL.S5] $=\{0.5,0.0,0.5,0.5\})=\{0.25,0.0,0.75,0.5\}$

$(\omega[E F$, user 1295,dr.REV.S5] $=\{0.333333333333333,0.0,0.666666666666667,0.5\}) \otimes$ $(\omega[$ user1295,texlipse,df.SOL.S5] $=\{0.333333333333333,0.0,0.666666666666667,0.5\})=$ $\{0.11111111111111088,0.0,0.8888888888888891,0.5\}$

$(\omega[$ EF, user1474,dr.REV.S5] $=\{0.333333333333333,0.0,0.666666666666667,0.5\}) \otimes$ $(\omega[$ user1474,texlipse,df.SOL.S5] $=\{0.333333333333333,0.0,0.666666666666667,0.5\})=$ $\{0.11111111111111088,0.0,0.8888888888888891,0.5\}$

$(\omega[$ EF,user1624,dr.REV.S5] $=\{0.333333333333333,0.0,0.666666666666667,0.5\}) \otimes$ $(\omega[$ user1624,texlipse,df.SOL.S5] $=\{0.333333333333333,0.0,0.666666666666667,0.5\})=$ $\{0.11111111111111088,0.0,0.8888888888888891,0.5\}$ 


\section{Consensus: $\omega$ [member $1 \diamond$ membern, solution]}

$(\omega[$ EF,user3708,dr.REV.S5] : [user3708,texlipse,df.SOL.S5] $=\{0.25,0.0,0.75,0.5\}) \oplus$ $(\omega[$ EF, user1295,dr.REV.S5] :

[user1295, texlipse,df.SOL.S5] $=\{0.11111111111111088,0.0,0.8888888888888891,0.5\}) \oplus$ $(\omega[$ EF,user1474,dr.REV.S5] :

[user1474,texlipse,df.SOL.S5] $=\{0.1111111111111088,0.0,0.8888888888888891,0.5\}) \oplus$ $(\omega[$ EF,user1624,dr.REV.S5] :

[user1624,texlipse,df.SOL.S5] $=\{0.11111111111111088,0.0,0.8888888888888891,0.5\})=$ $\{0.41463414634146306,0.0,0.5853658536585369,0.5\}$

\section{Consensus: $\omega$ [keystone.solution.if $\diamond$ keystone.solution.df, solution]}

$(\omega[$ EF, texlipse,df.SOL.S5] $=\{0.333333333333333,0.0,0.666666666666667,0.5\}) \oplus$ $(\omega[\mathrm{EF}$, texlipse, if.SOL.S5] $=\{0.41463414634146306,0.0,0.5853658536585369,0.5\})=$ $\{0.5471698113207543,0.0,0.45283018867924557,0.5\}$

7. Discounting: (customer : keystone) $\otimes$ (keystone : solution)

$(\omega[$ customer, $\mathrm{EF}]=\{0.3333333333333333,0.0,0.66666666666666666,0.5\}) \otimes$ $([\mathrm{EF}$, texlipse,, f $\oplus$ df.SOL.S5] $]=\{0.5471698113207543,0.0,0.45283018867924557,0.5\})=$ $\{0.1823899371069181,0.0,0.8176100628930818,0.5\}$

\section{Trust opinion values}

Belief $=0.1823899371069181$

Disbelief $=0.0$

Uncertainty $=0.8176100628930818$ 


\title{
Appendix $\mathrm{H}-$ Results of building a transitive trust network from customer to solution textlipse with simulated
}

\author{
observations on ability, benevolence, and integrity
}

\section{TNA-SL}

\section{Indirect Trust Arc}

[customer, texlipse, if.SOL.S5]

\section{Transitive Trust Paths}

[customer,EF] : [EF,user3708] : [user3708,texlipse] [customer,EF] : [EF,user1295] : [user1295,texlipse] [customer,EF] : [EF,user1474] : [user1474,texlipse] [customer,EF] : [EF,user1624] : [user1624,texlipse]

\section{Canonical Expression}

$([$ customer, texlipse] $])=([$ customer, EF] $):(([E F$, user3708] $:[$ user3708,texlipse] $) \diamond$ $([\mathrm{EF}$, user1295] : [user1295,texlipse] $) \diamond([\mathrm{EF}$, user1474] : [user1474,texlipse] $) \diamond([\mathrm{EF}$, user1624] : [user1624,texlipse]))

\section{Discounting: (keystone : members) $\otimes($ members : solution)}

$(\omega[\mathrm{EF}, \mathrm{user} 3708, \mathrm{dr} . \mathrm{REV} . \mathrm{S} 5]=\{0.5,0.0,0.5,0.5\}) \otimes$

$(\omega[$ user3708,texlipse,df.SOL.S5] $=\{0.5,0.0,0.5,0.5\})=\{0.25,0.0,0.75,0.5\}$

$(\omega[$ EF,user1295,dr.REV.S5] $=\{0.333333333333333,0.0,0.666666666666667,0.5\}) \otimes$ $(\omega[$ user1295,texlipse,df.SOL.S5] $=\{0.333333333333333,0.0,0.666666666666667,0.5\})=$ $\{0.1111111111111088,0.0,0.8888888888888891,0.5\}$

$(\omega[$ EF,user1474,dr.REV.S5] $=\{0.333333333333333,0.0,0.666666666666667,0.5\}) \otimes$ $(\omega[$ user1474,texlipse,df.SOL.S5] $=\{0.5,0.0,0.5,0.5\})=$ $\{0.1666666666666665,0.0,0.83333333333333335,0.5\}$

$(\omega[$ EF,user1624,dr.REV.S5] $=\{0.333333333333333,0.0,0.666666666666667,0.5\}) \otimes$ $(\omega[$ user 1624, texlipse,df.SOL.S5] $=\{0.5,0.0,0.5,0.5\})=$ $\{0.16666666666666665,0.0,0.83333333333333335,0.5\}$ 


\section{Consensus: $\omega$ [member $1 \diamond$ membern, solution]}

$(\omega[$ EF,user3708,dr.REV.S5] : [user3708,texlipse,df.SOL.S5] $=\{0.25,0.0,0.75,0.5\}) \oplus$ $(\omega[$ EF,user 1295,dr.REV.S5] :

[user1295,texlipse,df.SOL.S5] $=\{0.11111111111111088,0.0,0.8888888888888891,0.5\}) \oplus$ $(\omega[\mathrm{EF}, \mathrm{user} 1474, \mathrm{dr} . \mathrm{REV} . \mathrm{S} 5]$ :

[user1474,texlipse,df.SOL.S5] $=\{0.1666666666666665,0.0,0.8333333333333335,0.5\}) \oplus$ $(\omega[$ EF,user1624,dr.REV.S5] :

[user1624,texlipse,df.SOL.S5] $=\{0.1666666666666665,0.0,0.8333333333333335,0.5\})=$ $\{0.46188340807174866,0.0,0.5381165919282513,0.5\}$

6. Consensus: $\omega$ [keystone.solution.if $\diamond$ keystone.solution.df, solution]

$(\omega[$ EF,texlipse,df.SOL.S5] $]=\{0.5,0.0,0.5,0.5\}) \oplus$ $(\omega[$ EF,texlipse,if.SOL.S5] $=\{0.46188340807174866,0.0,0.5381165919282513,0.5\})=$ $\{0.6501457725947521,0.0,0.3498542274052479,0.5\}$

7. Discounting: (customer : keystone) $\otimes$ (keystone : solution)

$(\omega[$ customer, $\mathrm{EF}]=\{0.3333333333333333,0.0,0.6666666666666666,0.5\}) \otimes$

$([\mathrm{EF}$, texlipse,if $\bigoplus$ df.SOL.S5] $]=\{0.6501457725947521,0.0,0.3498542274052479,0.5\})=$ $\{0.21671525753158405,0.0,0.783284742468416,0.5\}$

\section{Trust opinion values}

Belief $=0.21671525753158405$

Disbelief $=0.0$

Uncertainty $=0.783284742468416$ 


\section{Appendix I - Template used in the output of results of}

\section{building a transitive trust network from customer to a}

\section{solution}

Placeholders for data collected by the web-crawler are represented in italics:

\section{TNA-SL}

\section{Indirect Trust Arc}

[customer, solution-code, if.SOL.scope-code]

\section{Transitive Trust Paths}

[customer, EF] : [EF, member1-code] : [memberl-code, solution-code] [customer, EF] : [EF, membern-code] : [membern-code, solution-code]

\section{Canonical Expression}

$([$ customer, solution-code $])=([$ customer, $\mathrm{EF}]):(([\mathrm{EF}$, member 1 -code $]:[$ member $1-$ code, solution-code $]) \diamond([\mathrm{EF}$, membern-code $]:[$ membern-code, solution-code $]))$

4. Discounting: (keystone : members) $\otimes$ (members : solution)

$\left(\omega[\mathrm{EF}\right.$, memberl-code,dr.REV.scope-code $\left.]=\left\{b_{x l}, d_{x l}, u_{x l}, a_{x l}\right\}\right) \otimes(\omega[$ memberl-code, solution-code, df.SOL.scope-code $\left.]=\left\{b_{y l}, d_{y l}, u_{y l}, a_{y 1}\right\}\right)=\left\{b_{1}, d_{1}, u_{1}, a_{1}\right\}$

$\left(\omega[\mathrm{EF}\right.$, membern-code, $\mathrm{dr}$.REV.scope-code $\left.]=\left\{b_{x n}, d_{x n}, u_{x n}, a_{x n}\right\}\right) \otimes(\omega[$ membern-code, solution-code, df.SOL.scope-code $\left.]=\left\{b_{y n}, d_{y n}, u_{y n}, a_{y n}\right\}\right)=\left\{b_{n}, d_{n}, u_{n}, a_{n}\right\}$ 


\section{Consensus: $\left(\right.$ member $\left._{1}\right) \oplus\left(\right.$ member $\left._{n}\right)$}

$(\omega[\mathrm{EF}$, memberl-code, dr.REV.S5] : [memberl-code, solution-code, df.SOL. scopecode $\left.]=\left\{b_{1}, d_{1}, u_{1}, a_{1}\right\}\right) \oplus(\omega[\mathrm{EF}$, membern-code, dr.REV. scope-code $]:$ [membern-code, solution-code,df.SOL.scope-code $\left.]=\left\{b_{n}, d_{n}, u_{n}, a_{n}\right\}\right)=\{b, d, u, a\}$

6. Consensus: (keystone.solution.if) $\oplus$ (keystone.solution.df)

$\left(\omega[\mathrm{EF}\right.$, solution-code, $\mathrm{df}$.SOL. scope-code $\left.]=\left\{b_{d f}, d_{d f}, u_{d f}, a_{d f}\right\}\right) \oplus(\omega[\mathrm{EF}$, solution-code, if.SOL. scope-code $\left.]=\left\{b_{l f}, d_{l f}, u_{l f}, a_{l f}\right\}\right)=\left\{b_{d f \oplus 1,}, d_{d f \oplus l f}, u_{d f \oplus l f}, a_{d f \oplus l f}\right\}$

7. Discounting: (customer : keystone) $\otimes$ (keystone : solution)

$\left(\omega[\right.$ customer, EF, dr.KEY. scope-code $]=\left\{b_{d r}, d_{d r}, u_{d r}, a_{d r}\right\} \otimes[\mathrm{EF}$, solution-code, if $\oplus$ df.SOL. scope-code $\left.]=\left\{b_{d f \oplus I,}, d_{d f \oplus I,} u_{d f \oplus I,} a_{d f \oplus I f}\right\}\right)=\{b, d, u, a\}$

\section{Trust opinion values}

Belief $=b$

Disbelief $=d$

Uncertainty $=u$

In the template used for the output content of buildTransitiveTrustNetwork() method shown in this appendix I we have the following parts:

1. Indirect trust arc: a representation of the indirect trust arc between the customer and the solution. The notation used follows the pattern [truster, trustee, scope variant.scope].

2. Transitive trust paths: a list of all possible paths between the customer and the solution considering the keystone and all marketplace members that had provided some feedback about the solution. EF is the keystone-code for Eclipse. 
3. Canonical expression: the canonical expression for all transitive trust paths between the customer and the solution.

4. Discounting: (keystone : members) $\otimes$ (members : solution): a discounting operation for each transitive trust path between the keystone and the solution. The result of each operation is a discounted trust opinion ( $\omega=\{$ belief, disbelief, uncertainty, a-priori trust \}) for each transitive trust path

5. Consensus: $\left(\right.$ member $\left._{1}\right) \oplus\left(\right.$ member $\left._{n}\right)$ : a consensus operation is made for all discounted opinions. The result of this operation is a new consensual opinion derived from the opinion of all members in the transitive trust paths between the customer and the solution.

6. Consensus: (keystone.solution.if) $\oplus$ (keystone.solution.df): a second consensus operation is made, now between the keystone direct functional trust opinion about the solution (based on the direct observations of the keystone to the solution) and the consensual opinion derived from the opinion of all members (result of previous consensus operation)

7. Discounting: (customer : keystone) $\otimes$ (keystone : solution): a second discounting operation is made, now between the opinion of the customer about the keystone and the consensual opinion of the keystone about the solution (result from previous step).

8. Trust opinion values: The result of all steps is the trust opinion values for belief, disbelief, and uncertainty of the customer about the solution.

\section{Appendix J - Transitive Trust Network Model}


The key features of a transitive trust network model for a marketplace operated by a keystone are:

a. A keystone operates the marketplace where members can announce their solutions

b. Customers find about members through the marketplace

c. Customers go to the marketplace because they have some level of initial trust on the keystone

d. Other members provide their views about announced solutions

e. The customer can, therefore, derive indirect trust to the solution from the keystone and from members

Figure 15 illustrates the high level visualization of the trust path between the customer and a solution in the marketplace.

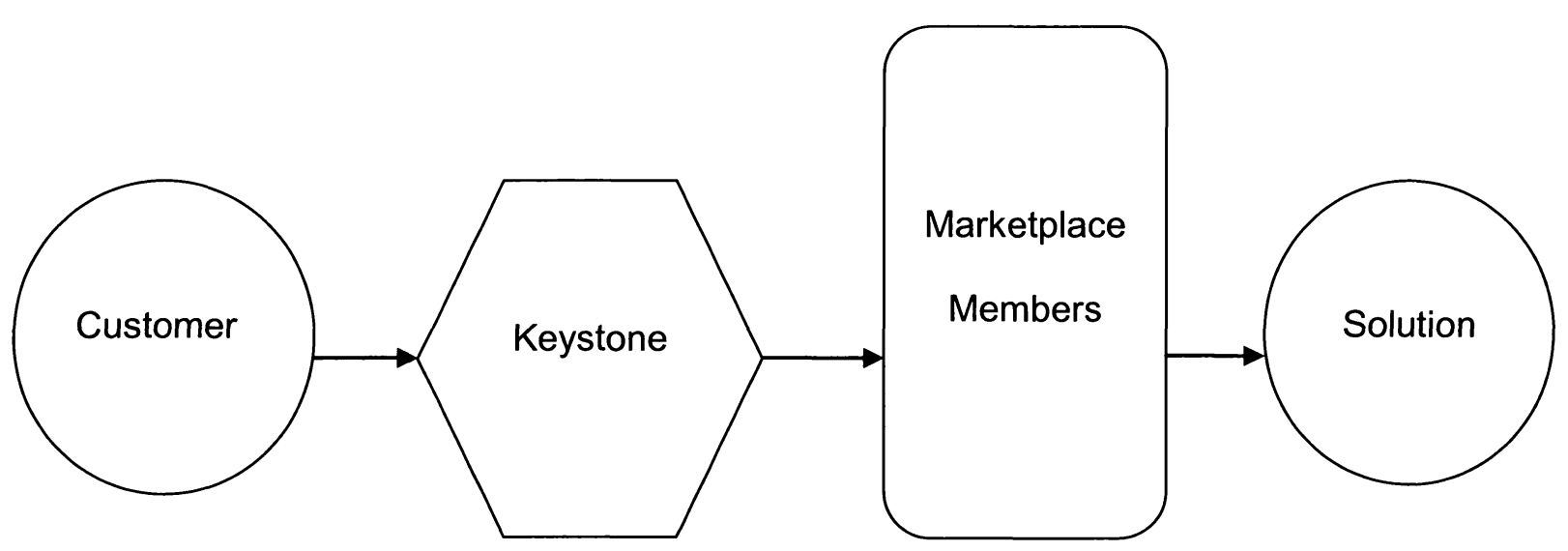

Figi Figure 15: Trust path between customer and a solution in a marketplace keystone. The keystone trusts marketplace members and offers them a space to 
announce solutions and review other members' solutions. Marketplace members work as referrals by providing their views about solutions published. The keystone also works as a referral to marketplace members and their solution.

The indirect trust from the customer to the solution is derived from observations about the ability, integrity and benevolence of the solution supplier.

Figure 16 illustrates the relationship between the three trust dimensions and the transitivity of a trust opinion. It uses the same trust path customer : keystone : marketplace members : solution.

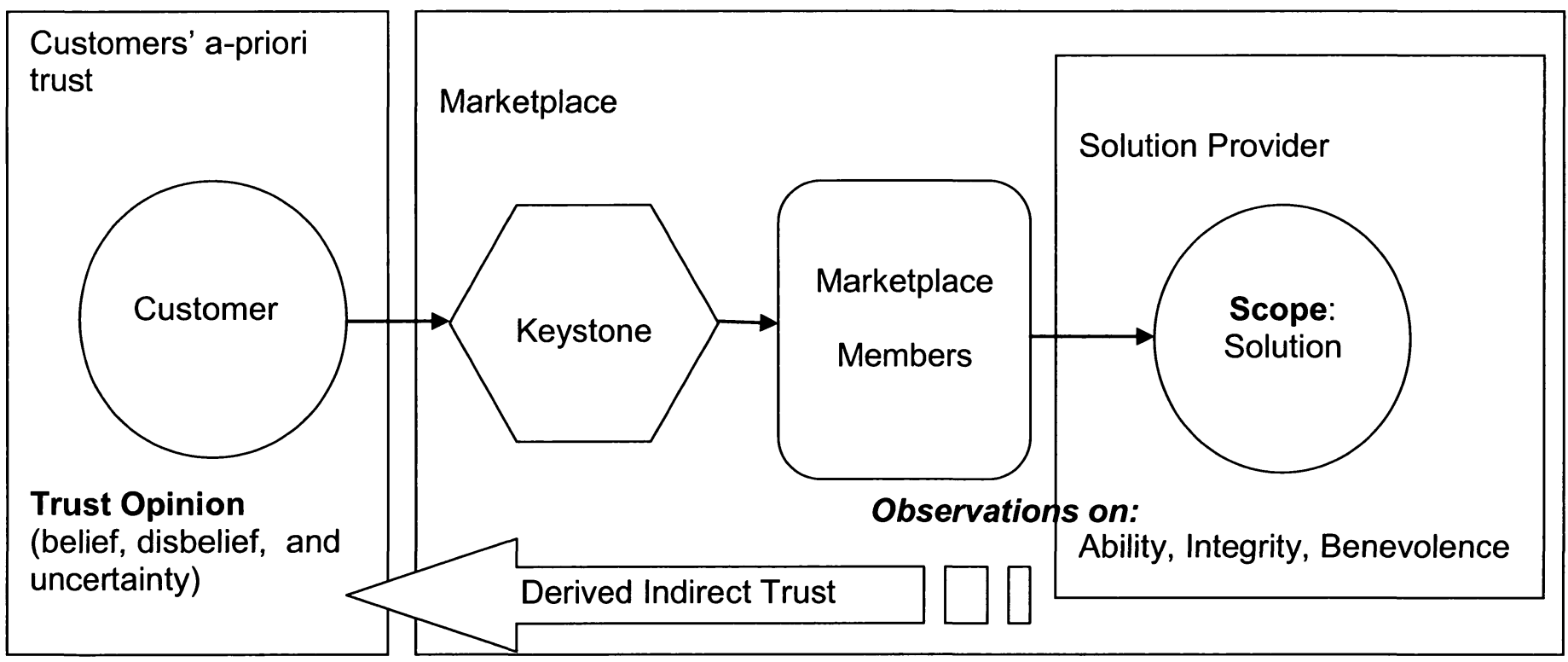

Figure 16: Detailed trust model for a marketplace

The trust model in Figure 16 illustrates the following: 
a) Customer arrives with its own initial a-priori trust on the keystone.

b) Customer goes to the marketplace looking for information about "Solution".

c) Keystone and marketplace members provide observations about "Solution".

d) "Solution" is the trust scope.

e) Observations from the marketplace's keystone and members about the solution supplier's ability, integrity, and benevolence are used as indirect trust evidence to compute a derived trust opinion.

f) A final customer's trust opinion that will define the level of belief, disbelief, and uncertainty of the customer on the solution can be calculated. 